EGG-FSP-11109

ITER/93/US/EN/SA-7

\title{
Requirements for U.S. Regulatory Approval of the International Thermonuclear Experimental Reactor (ITER)
}

\author{
D. A. Petti \\ J. C. Haire \\ Published December 1993 \\ Idaho National Engineering Laboratory \\ EG\&G Idaho, Inc. \\ Idaho Falls, Idaho 83415
}

Prepared for the

U.S. Department of Energy

Office of Fuslon Energy

Under DOE Idaho Operations Office

Contract DE-AC07-76ID01570

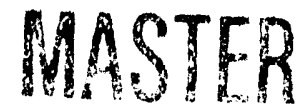




\section{EXECUTIVE SUMMARY}

The International Thermonuclear Experimental Reactor (ITER) is the first fusion machine that will have sufficient decay heat and activation product inventory to pose potential nuclear safety concerns. As a result, nuclear safety and environmental issues will be much more important in the approval process for the design, siting, construction, and operation of ITER in the United States than previous fusion devices, such as the Tokamak Fusion Test Reactor. The purpose of this report is (a) to provide an overview of the regulatory approval process for a Department of Energy (DOE) nuclear facility; (b) to present the dose limits used by DOE to protect workers, the public, and the environment from the risks of exposure to radiation and hazardous materials; (c) to discuss some key nuclear safety-related issues that must be addressed early in the Engineering Design Activities (EDA) to obtain regulatory approval; and (d) to provide general guidelines to the ITER Joint Central Team (JCT) concerning the development of a regulatory framework for the ITER project.

The regulatory approval process for a DOE nuclear facility in the United States is best understood in the context of the total life cycle of a DOE major system acquisition. This life cycle includes a number of major phases that involve interfacing between the owner-operator, government regulatory bodies, and other federal and state agencies. For ITER, the owneroperator is the ITER JCT, and the government regulatory body is the U.S. Department of Energy (DOE). In addition, DOE acts as agent for other regulatory requirements from other agencies, such as the Environmental Protection Agency, the Department of Transportation, or the Department of Interior. The interfacing produces briefings, document submittals, reviews, evaluations, inspections, concurrences, and approvals, which make up the U.S. DOE regulatory approval process. The following are typical life cycle phases of a DOE facility major system acquisition:

- Baseline requirements (mission, need, and functional and operational requirements)

- National Environmental Policy Act considerations (environmental assessments, environmental impact statements and records of decision)

- Design (Conceptual, Title I, and Title II designs)

- Safety analysis (hazard assessments and categorization, preliminary and final safety analyses, and technical safety requirements)

- Construction (acquisition, test, assembly, and Title III design)

- Operation (operational readiness reviews, staffing, program execution and facility modifications)

- Decommissioning (cleanup, waste management, and site restoration).

An important part of the DOE regulatory process is the protection of workers, the public, and the environment from the risks of exposures to radiation and hazardous materials. The applicable DOE orders specifically implement radiation protection standards that are consistent 
with those used by the U.S. Nuclear Regulatory Commission and those recommended by the International Commission on Radiological Protection. In setting these criteria, DOE's objective is to maintain potential radiation exposures to the workers and the public as low as reasonably achievable and to monitor routine and nonroutine releases from facilities. Radiological dose limits have been developed for both normal and accidental releases of radioactive material to the environment, for worker exposures, for emergency planning, and for requirements to dispose of radioactive waste.

A review of the DOE design and safety orders identified a number of key nuclear safety related issues that have received less attention in the design and construction of previous fusion facilities. However, the following issues must be addressed early in the ITER EDA to develop a credible case for obtaining regulatory approval in the U.S. and to prevent major rework in the design and in research and development activities:

- Safety analysis requirements

- Overall level of quality assurance required for the project

- Definition of safety class items for ITER, corresponding design standards, and the level of testing required to qualify such items

- Verification and validation of computer codes

- Experimental databases needed for final design and for the regulatory approval process

- Level of technical understanding

- Tritium accountability

- Emergency planning.

The report discusses these issues and potential methods of implementation. How the JCT incorporates requirements in these areas into their regulatory framework will have a large impact on the scope and resources for safety, design, and research and development tasks. The effort in each area should be proportional to the relative risk of each activity. Compliance with these requirements should be achieved using as practical an approach as possible while still meeting the spirit of the requirement.

ITER will be a first-of-a-kind machine and will pose unique regulatory concerns. A significant amount of time should be devoted to educating regulators about fusion, ITER, and its project management approach to safety so that fusion technology is understood. The following guidelines are recommended for the ITER JCT to develop a regulatory framework that is beneficial to ITER and fusion:

- Maintain an approach that focuses on needs of fusion and ITER to ensure that the requirements of this technology are foremost in the decision processes and that the 
history and experience of the fission industry are kept in proper perspective, neither being blindly adopted nor summarily dismissed.

- Recognize ITER's experimental nature in the development of regulatory requirements.

- Focus on hazard reduction and passive or inherent safety design solutions as a means of preventing accidents.

- Implement a graded approach policy in the overall management of the project such that all requirements are proportionate to the associated risk.

- Integrate the use of risk- and cost-benefit analyses into the overall graded approach system to help guide the development of regulatory requirements as much as possible.

- Implement a policy of detecting and fixing problems at the source at the earliest time possible.

- Highlight in the process to review and adopt ITER requirements the importance of not stifling innovative approaches in design and safety by the adoption of any requirement.

- Implement a configuration management policy that will result in a minimum number of separate documents used to define requirements, thus reducing the potential for contradiction and conflict, and enhancing the probability of always being in compliance.

- $\quad$ Structure the baseline development task to identify the information required for ITER planning in such a way that the Home Teams can both participate in the identification of all relevant requirements for their countries and also monitor changes in their countries' requirements. Charge the Home Teams with keeping the JCT informed of all relevant regulatory developments. Delegate to the home teams the lead responsibility for negotiation of waivers and exclusions of potential host country requirements.

This report was developed primarily from the requirements for DOE nuclear facilities that are designed, built, and operated in the U.S. Although DOE guidance has been the source of the requirements discussed, the motivation for most of the requirements transcends DOE, the U.S., and any other regulatory or national considerations. The requirements are those used by management for any major nuclear undertaking. As such, they should be accepted as a foundation by the JCT for success of the ITER project, no matter which country is ultimately selected to host the facility. Accordingly, the approach presented in this report should be recognizable in the final ITER regulatory approach framework that will be adopted by the Parties. Further, that regulatory framework should incorporate the baseline requirements in the ITER project management plan regardless of the siting decision ultimately made by the Parties. 


\section{FOREWORD}

This report was prepared for the Joint Central Team (JCT), who requested a documented description of the process needed to obtain regulatory approval for the design, construction, operation, and decommissioning of the International Thermonuclear Experimental Reactor (ITER) in the United States (U.S.). The report provides an overview of requirements for siting, construction, operation, and eventual decommissioning of ITER. At this time there is NO accepted, approved, agreed to process for obtaining such U.S. regulatory approval of a fusion machine such as ITER. The process described in this report has been interpreted from the existing directives for U.S. Department of Energy (DOE) nuclear facilities. The existing process was not structured for fusion machines. However, it exists and is probably the one that the owner-operator of a fusion machine would have to use to obtain regulatory approval of a facility. The process presented in this report also discusses the elements of the current regulatory approval process that must be explicitly addressed by the fusion community to obtain either waivers or exclusions from requirements that do not apply or to initiate changes in the requirements to make them relevant to fusion.

This report provides a top-level, summary view of the overall process of obtaining U.S. government regulatory approval for the operation of a nuclear facility in the U.S. The process includes all precedent and followup requirements. Because the process reflects the history of fission facilities in the U.S., it may or may not be sufficient for the management of fusion machines. However, the process reflects the existing structure against which the needs and requirements of fusion must be weighed to develop the ITER regulatory approval process.

The process described in this report is generic. While some of the requirements cited may not be directly applicable to ITER, the generic nature of the requirements, such as siting and safety analysis, must be implemented for ITER, as with any other nuclear facility activity.

Being an overview, the report does not describe all of the detailed requirements for the management of the ITER program. The development of the comprehensive, detailed set of requirements must be the first task of ITER's owner-manager. This task is described in this report as baseline requirements definition for the overall regulatory review process.

The responsibilities and authorities of the owner-operator of the facility who seeks regulatory approval are stated in the U.S. government documents. In the case of ITER, the owner-operator is expected to be an entity selected by the Parties (i.e., United States, European Community, Russian Federation, and Japan) at some later stage in the ITER life cycle. The responsibilities of the JCT have been defined by the Parties to stop when the ITER design is complete. This situation results in a default condition of not having a designated owner-operator, but having a limit on the JCT scope of responsibilities. This report addresses the default condition by making the JCT the customer for all findings in this report with the expectation that either the U.S. Home Team or the JCT will bring the situation to the Parties for their decision as soon as possible. However, all participants must recognize that the regulatory framework for ITER will be developed during the design in response to both ITER needs and regulatory requirements in the candidate site countries. Thus, the JCT will make the decisions as the architect and as the owner of the ITER regulatory framework. In this ownership role, the JCT is primary audience and customer for this report. 
The regulatory approval process consists of many actions that are directly affected by nuclear safety related requirements. These actions are especially significant for the design process.

Accordingly, these nuclear safety related requirements must be identified and addressed early in the Engineering Design Activity (EDA). This report addresses many requirements that the fusion community historically has not had to address because previous fusion experimental machines have not had the substantial decay heat and large inventories of tritium and activation products associated with ITER. The activities of the fusion community are inherently different from most DOE activities (i.e., fission reactors, fuel processing, and waste management) for which the DOE regulatory requirements were developed. The requirements discussed in this report originated primarily from the approximately $500 \mathrm{DOE}$ orders, notices, and directives that were related to nuclear safety and design activities. Because many DOE orders and guidance standards are being revised, the information could change the details in this report. In addition, more changes will be initiated, and new orders and other directives will be generated throughout the life cycle of ITER. This report was designed to suggest a baseline that can be updated as significant changes occur in the regulatory requirements.

When we speak of an ITER or JCT regulatory approach framework, we mean the overall management system for producing regulatory approval. This framework includes the policies established, the approaches to be taken on any task, the assignment of authorities and responsibilities, and the measurements and followup used to ensure that planned actions are completed within allocated resources.

Throughout the report, we have cited EG\&G Idaho, Inc., and systems, processes, or experiences at the Idaho National Engineering Laboratory (INEL). These citations illustrate how specific problerns and issues have been addressed at one DOE site. We do not wish to connote any absolute uniqueness or claim of discovery by these citations.

Although we have focused on DOE and its requirements, the fundamental technical requirements are characteristic of any professionally planned and managed nuclear entity. Therefore, these fundamental technical requirements should be reflected in the ITER project management documentation regardless of its siting and its national operational management decisions.

We do not wish to make recommendations to the JCT. However, we want to highlight all issues that are useiui to structuring a disciplined approach for obtaining regulatory approval. 


\section{CONTENTS}

EXECUTTVE SUMMARY $\ldots \ldots \ldots \ldots \ldots \ldots \ldots \ldots \ldots \ldots \ldots \ldots \ldots$ iii

FOREWORD $\ldots \ldots \ldots \ldots \ldots \ldots \ldots \ldots \ldots \ldots \ldots \ldots \ldots \ldots \ldots \ldots \ldots \ldots \ldots \ldots$

ACRONYMS $\ldots \ldots \ldots \ldots \ldots \ldots \ldots \ldots \ldots \ldots \ldots \ldots \ldots \ldots \ldots \ldots \ldots \ldots \ldots$

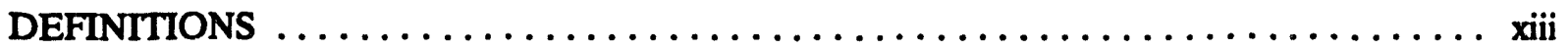

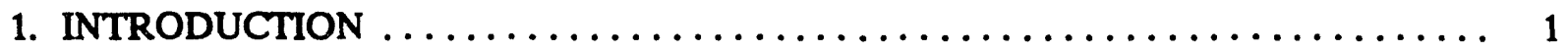

2. REGULATORY APPROVAL PROCESS FOR A U.S. DOE NUCLEAR FACILITY $\ldots \quad 2$

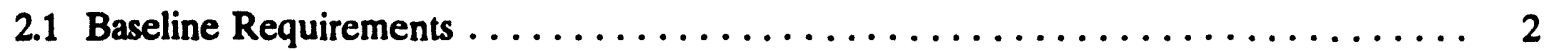

2.2 National Environmental Policy Act Considerations .................. 5

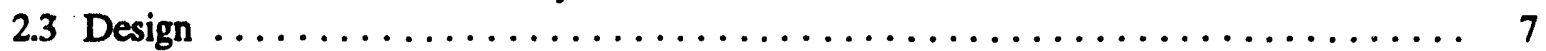

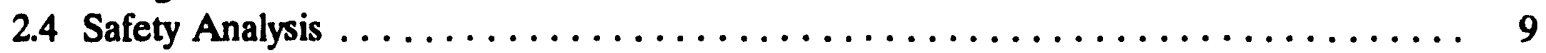

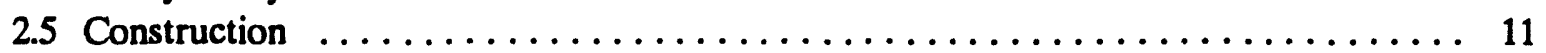

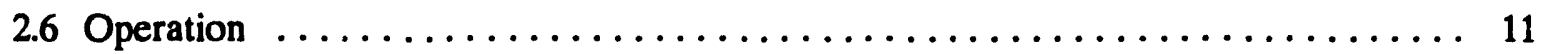

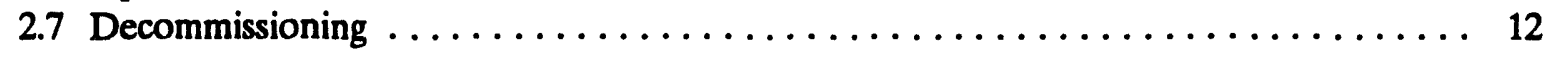

3. RADIOLOGICAL AND BERYLLIUM SAFETY CRITERIA $\ldots \ldots \ldots \ldots \ldots \ldots \ldots$

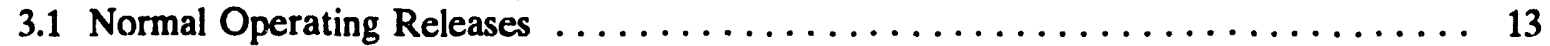

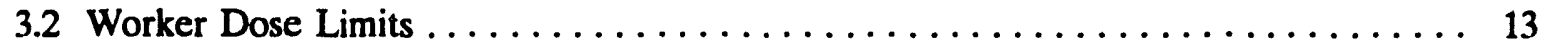

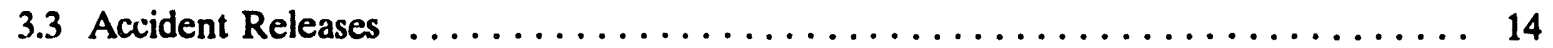

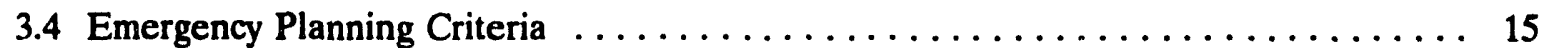

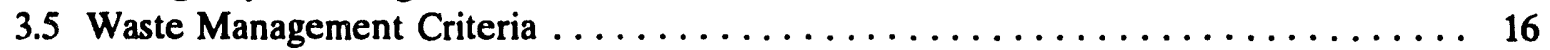

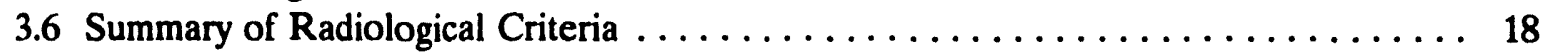

3.7 Beryllium Exposure Limits $\ldots \ldots \ldots \ldots \ldots \ldots \ldots \ldots \ldots \ldots \ldots \ldots \ldots \ldots$

4. NUCLEAR SAFETY-RELATED TECHNICAL ISSUES $\ldots \ldots \ldots \ldots \ldots \ldots \ldots \ldots$

4.1 Safety Analysis, Hazard Classification, and the Graded Approach . . . . . . . . . 21

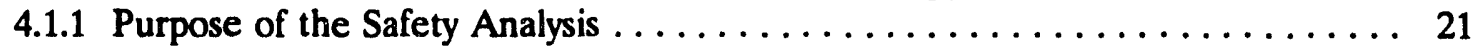

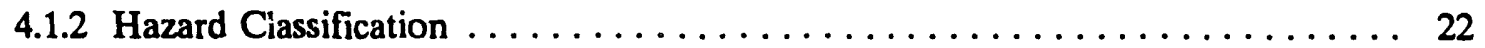

4.1.3 Contents of the Safety Analysis Report ................... 24

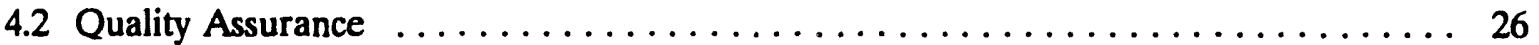

4.3 Safety Class Items . . . . . . . . . . . . . . . . . . . . . . . . . . . 29

4.4 Verification and Validation of Computer Codes $\ldots \ldots \ldots \ldots \ldots \ldots \ldots \ldots \ldots \ldots$

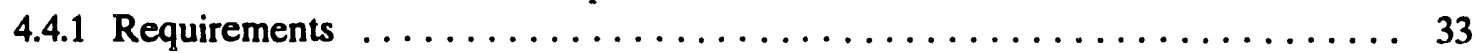

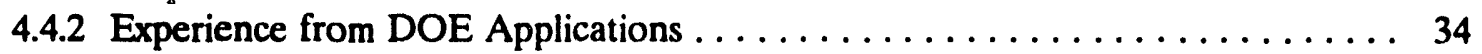

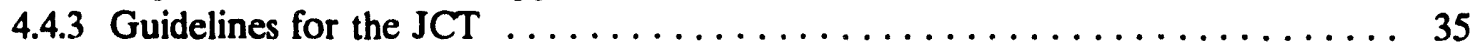

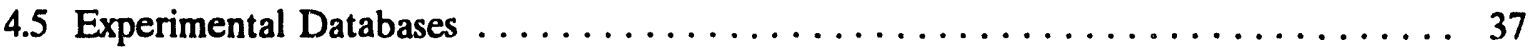

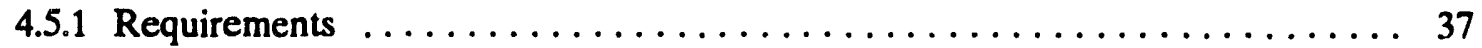

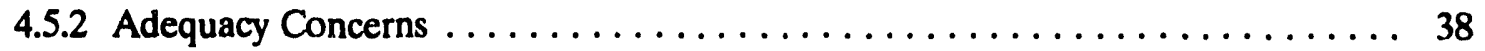

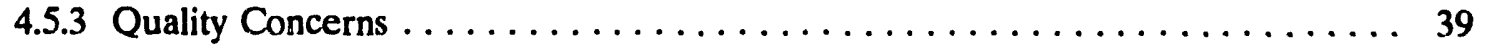

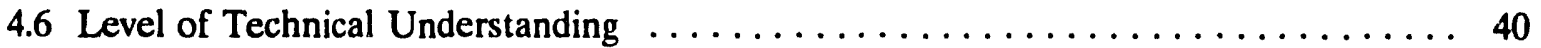

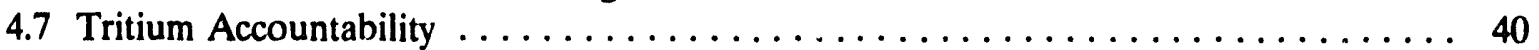


5. GUIDELINES FOR THE JCT $\ldots \ldots \ldots \ldots \ldots \ldots \ldots \ldots \ldots \ldots \ldots \ldots \ldots \ldots$

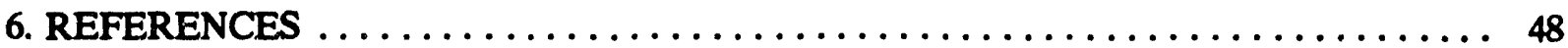

\section{FIGURES}

1. Typical life cycle for DOE facility regulatory approval $\ldots \ldots \ldots \ldots \ldots \ldots \ldots \ldots$

2. National Environmental Policy Act (NEPA) process $\ldots \ldots \ldots \ldots \ldots \ldots \ldots \ldots$

3. Project time line for compliance with environmental requirements $\ldots \ldots \ldots \ldots \ldots \ldots 8$

\section{TABLES}

1. Guidelines for offsite doses $\ldots \ldots \ldots \ldots \ldots \ldots \ldots \ldots \ldots \ldots \ldots \ldots \ldots \ldots \ldots \ldots$

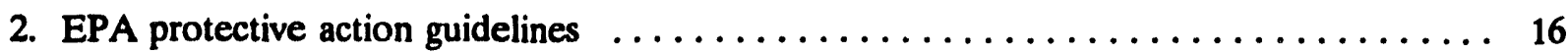

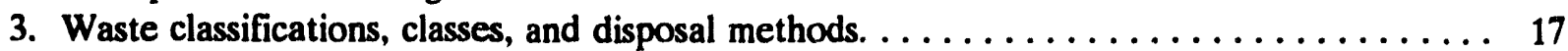

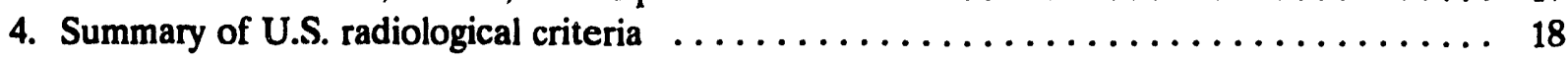

5. Hazard assessments, emergency classes, and PAG limits $\ldots \ldots \ldots \ldots \ldots \ldots \ldots \ldots$ 


\section{ACRONYMS}

\begin{tabular}{ll} 
ALARA & As low as reasonably achievable \\
ANSI & American National Standards Institute \\
ASME & American Society of Mechanical Engineers \\
ATR & Advanced Test Reactor \\
CDA & Conceptual Design Activities \\
CZMA & Coastal Zone Management Act \\
D\&D & Decontamination and decommissioning \\
DBA & Design basis accident \\
DEIS & Draft environmental impact statement \\
DIII-D & Tokamak at General Atomics (no acronym - just the name) \\
DOE & Department of Energy \\
DOE-OFE & Department of Energy-Office of Fusion Energy \\
DOI & Department of Interior \\
DOT & Department of Transportation \\
DRC & Data Review Committee \\
EDA & Engineering Design Activities \\
EDE & Effective dose equivalent \\
EIS & Environmental impact statement \\
EPA & Environmental Protection Agency \\
EPZ & Emergency planning zone \\
FEIS & Final environmental impact statement \\
F\&OR & Functional and Operational Requirements \\
FSAR & Final safety analysis report \\
ICRP & International Commission on Radiological Protection \\
IEEE & Institute for Electrical and Electronic Engineers \\
INEL & Idaho National Engineering Laboratory \\
ITER & International Thermonuclear Experimental Reactor \\
JCT & Joint Central Team \\
JET & Joint European Torus \\
JT-60 & Japanese Tokamak \\
LOCA & Loss-of-coolant accident \\
MSHA & Mine Safety and Health Act \\
NEPA & National Environmental Policy Act \\
NHPA & National Historic Preservation Act \\
NIOSH & National Institute of Occupational Safety and Health \\
NOI & Notice of Intent \\
NQA & Nuclear Quality Assurance \\
NRC & Nuclear Regulatory Commission \\
ORR & Operational Readiness Review \\
OSHA & Occupational Safety and Health Administration \\
PAG & Protective action guideline \\
PSO & Program Secretarial Official \\
PSAR & Preliminary safety analysis report \\
QA & Quality assurance \\
R\&D & Research and development \\
\hline &
\end{tabular}


ROD Record of Decision

SAR Safety analysis report

SCI Safety class item

SPERT IV Special Power Excursion Reactor Test IV

TFIR Tokamak Fusion Test Reactor

TSR Technical safety requirement

U.S. United States

V\&V Verification and validation 


\section{DEFINITIONS}

Design Basis - the requirements that bound the design of systems, structures, and components within the facility. The design requirements include consideration of safety, plant availability, efficiency, reliability, and maintainability. Some aspects of the design bases are important to safety; others are not.

Design Basis Accidents (DBAs) - accidents that are postulated for establishing functional requirements for safety significant structures, systems, components, and equipment.

Beyond Design Baxis Accidents - accidents that are postulated that could result in consequences beyond those established for the facility-specific design basis accidents.

Safety Analysis - the documented process that (a) systematically identifies hazards within a given DOE operation; (b) describes and analyzes the adequacy of measures taken to eliminate, control, or mitigate identified hazards; and (c) analyzes and evaluates potential accidents and their associated risks.

Safety Easis - the combination of information relating to control of hazards at a facility (including design, engineering analysis, and administration controls) that supports the DOE conclusion that activities at the facility can be conducted safely.

Safety Class Items - the systems, components, and structures, including portions of process systems, whose failure could adversely affect the safety and health of the public, facility personnel, and site workers, and cause unacceptable impact to the environment.

Safety Function - the required function(s) to be accomplished before, during, and after a design basis event to ensure the health and safety of the public, as stated in the safety analysis report.

Technical Safety Requirements (TSRs) - requirements that define the conditions, safe boundaries, and the management and administrative controls necessary to operate a nuclear facility safely and to reduce the potential risk to the public and facility workers from uncontrolled releases of radioactive materials or from radiation exposure resulting from an inadvertent criticality. A TSR consists of operating limits, surveillance requirements, administrative controls, use and application instructions, and the bases thereof.

Graded Approach - a process by which the level of analysis, documentation, and actions necessary to comply with a requirement are commensurate with (a) the relative importance to safety, safeguards, and security; (b) the magnitude of any hazard involved; (c) the life-cycle stage of any facility; (d) the programmatic mission of a facility; (e) the particular characteristics of a facility; and (f) any other relevant factor. 


\section{Requirements for U.S. Regulatory Approval of the International Thermonuclear Experimental Reactor (ITER)}

\section{INTRODUCTION}

The process of obtaining approval to site, design, construct, and operate ${ }^{\mathrm{a}}$ the International Thermonuclear Experimental Reactor (ITER) will present many challenges to the world fusion community. ITER is the first fusion machine that will have sufficient decay heat and tritium and activation product inventories to pose potential public safety concerns. As a result, nuclear safety and environmental issues should receive significantly more attention than was given to current fusion machines, such as the Joint European Torus (JET), DIII-D, Japan's Tokamak (JT-60) and the Tokamak Fusion Test Reactor (TFTR). Because ITER represents a first-of-a-kind large fusion facility, it will be perceived as foretelling the safety and environmental characteristics of future fusion power plants, and will set a precedent regarding their regulatory approval process.

There is no specific Department of Energy (DOE) regulatory framework or process in the United States (U.S.) for regulatory approval of a fusion machine like ITER. However, the existing framework for regulatory approval of DOE nuclear facilities is fairly broad and deals with radiological and other risks. DOE has begun work on the development of an order governing the safety of fusion test facilities (5480.FUSION) and an associated guidance standard. However, development, review, and approval of these documents is not expected for about 2 years.

The process of obtaining U.S. DOE regulatory approval for ITER will require compliarce with numerous regulatory agencies [e.g., DOE, Department of Transportation (DOT), Department of Interior (DOI), and Environmental Protection Agency (EPA), state, and local]. Their directives address nuclear safety, siting, design, construction, operation, training, transportation, air and water quality, land use, security, and administration. This report presents an overview of the process to obtain approval for the design, siting, construction, and operation of ITER in the U.S. and also discusses the nuclear safety related requirements that impact the design and research and development (R\&D) activities of the project.

Section 2 presents a broad overview of the regulatory approval process for ITER. Section 3 presents the current radiological dose criteria applicable to DOE facilities in the U.S. Key nuclear safety related issues that should be addressed by the ITER project early in the Engineering Design Activity (EDA) are discussed in Section 4. Early attention to these issues will ensure that the design and safety activities contribute to a credible regulatory case in the U.S. Section 5 discusses some general guidelines to help the Joint Central Team (JCT) develop a successful regulatory framework. References are provided in Section 6.

a. The term licensing is not strictly applicable to U.S. DOE facilities. DOE does not grant a license for its facilities. Instead, DOE grants authorization to operate the facility. The term licensing has historically been used by the U.S. Nuclear Regulatory Commission (NRC) to grant approval for operation of commercial fission reactors. As a result, the term licensing is not used here. 


\section{REGULATORY APPROVAL PROCESS FOR A U.S. DOE NUCLEAR FACILITY}

The process of obtaining approvals for the siting, design, operation, and eventual decommissioning of a DOE facility in the U.S. involves numerous steps, a variety of interfacing actions. and many documents. To our knowledge, there is no one single reference that contains the entire process. Furthermore, the situation could change as new DOE orders are implemented or new precedents or interpretations are made. The details of the process cannot be fully predicted until the exact ITER design is subjected to the formal process.

Generally, the process is similar to the process used for any major facility acquisition and operation, starting with documentation of the baseline requirements. The process then continues through all life cycle phases and ends with site restoration. The regulatory approval process involves interfacing with many governmental elements, some of which provide requirements and some of which are legislated or delegated as agents for requirement actions. This section discusses the requirements for each life cycle phase of a typical facility and identifies the most relevant nuclear safety requirements, the source of the requirements, and the nature of the effort required to reach compliance with the requirements. The discussion of the effort includes the documents required, the interfaces with organizations, and the ultimate authorities for review and approval. In some cases, time and other resource estimates are provided, based on experience with other DOE activities.

Figure 1 lists the typical life-cycle phases addressed in this section and representative component elements for each phase. The purpose of this section is to provide a comprehensive overview. Section 4 of this report will address nuclear safety related technical issues in greater detail. The purpose of Section 4 is to communicate to the fusion community sufficient information about these issues to support their important role in the ITER project. These elements have not received the attention, priority, or planning to match their importance to the safety of ITER.

\subsection{Baseline Requirements}

The first step in the regulatory approval process is planning and preparation, which consists of documenting all baseline requirements for the activity. While the definition of these baseline requirements may not be perceived as a part of the regulatory process, it is necessary for an efficient, effective, and successful regulatory approval process. These requirements include the mission and need statements, definition of all regulatory products, and a comprehensive list of all requirements.

The mission and need statements are written by the owner-operator and the program funding source. In the case of ITER, the JCT would be the agent for the program funding source (the Parties) and would also be the owner-operator until an operating contractor is selected.

The functional and operational requirements (F\&ORs) for the activity must be documented as early as possible in the facility life cycle. The F\&ORs are used for all aspects of the regulatory 
UIFE-CYCLE PHASES

Baseline Requirements

NEPA Considerations

Design

Safety Analysis

Construction

Operation

Decommissioning

\section{SELECTED COMPONENT ELEMENTS}

mission and need definition functional \& operational requirements systems engineering flow chart program plan project management plan negotiated exclusions \& waivers memoranda of understanding

environmental assessment environmental impact statement public involvement record of decision siting

conceptual design plan requirements definition design records \& reports specifications design analyses trade-off studies make-buy reviews

hazards assessment risk assessment safety analysis reports technical safety requirements

procurement component testing vendor data fabrication process verification construction inspection

component checkout tests system operational testing integrated plant tests operational readiness review configuration management modifications maintenance

\section{D\&D plan}

decontamination waste management site restoration

a. Plans, procedures, and records of results are generic elements in all phases.

Figure 1. Typical life cycle for DOE facility regulatory approval. 
process. They are also a dynamic product of the systems engineering process that describes the entire facility acquisition and regulatory approval activity. As such, the F\&ORs will be revised as necessary to demonstrate that the ITER design complies with the specific requirements at all given times.

One of the most important elements of the baseline requirements phase is the definition of specific regulatory products, such as the Environmental Impact Statement (EIS), the Preliminary Safety Analysis Report (PSAR), and the Final Safety Analysis (FSAR). These documents and their review and approval actions define a critical aspect of the planning process. Knowing who will review and approve (names, organizations, and positions), the schedule, and the purpose for the reviews and approvals, throughout the activity life cycle will greatly speed the process. For ITER, all specific persons, agencies, and documents that are described generically in this section cf the report must be identified.

This section is based on our knowledge of current U.S. DOE requirements. The JCT must manage the baseline requirements development task to ensure that the task will identify and incorporate new requirements. In this regard, the DOE has published proposed nuclear safety rules (DOE Rules) that when finally adopted by DOE are expected to supersede DOE orders on the same subjerts. Therefore, monitoring the progress toward implementation of the rules and incorporating them into the baseline requirements development as soon as possible would benefit ITER.

Being an overview, this section does not identify a comprehensive list of requirements that must be addressed. The total list is the responsibility of the baseline requirements task for ITER. However, to suggest the magnitude of this task, a list of sources for the requirements includes DOE, EPA, DOT, DOI, Department of Defense, Department of Labor, and Department of State. Documents that contain requirements include DOE Orders, Notices, and Standards; Secretary of Energy Notices and Directives; DOE Field Office Orders, Notices, and Procedures; federal laws implemented by DOE, such as the National Environmental Policy Act (NEPA), Occupational Safety and Health Act of 1970 (OSHA), National Historic Preservation Act (NHPA), Coastal Zone Management Act of 1972 (CZMA), and Mine Safety and Health Act (MSHA). Additional requirements come from state legislation and state agency regulations and directives.

Because a blanket application of requirements contributes to inefficiencies and cost ineffectiveness, each element proposed for inclusion in the baseline requirements must be assessed for its relevance to ITER. The process allows the owner-operator to seek a waiver or exclusion based on adequate justification. Thus, irrelevant environment, safety, and health requirements can be dropped as long as the rigor of the "graded approach" can be demonstrated. Implementation plans, which describe the managed actions required, are now used for all orders issued by DOE to contractors for compliance. Formal records of all such negotiated waivers and exclusions will be an essential program management item. The provisions for them should be highlighted in the baseline requirements planning.

This report discusses DOE and other requirements as they are presented in the requirements documents. This is not to imply that they have been evaluated and accepted or 
recommended for ITER. That evaluation and acceptance is part of the baseline requirements definition process.

The use of standards and codes for ITER will be addressed as part of the baseline requirements development. Although formal requirements for the identification and application of standards and codes are stated in some DOE orders, the facility management must implement the fundamental requirement. Codes and standards are an important part of the basic safety and engineering documentation for every major technological activity. The applicable existing codes and standards must be defined and a formal process developed to apply the standards throughout the life of the facility and to develop other standards where needed. This activity could be a unique opportunity for ITER to contribute significantly to standards development for the fusion community.

This report focuses on U.S. requirements only. However, the requirements of all potential host countries must be factored into the ITER plans. Because the JCT may not be able to monitor the changing requirements, the JCT must create an information structure that will allow the home teams to participate in the identification of all relevant requirements for their countries and monitor changes in their country's requirements. Their efforts will keep the JCT informed of all relevant developments. In addition, the JCT should delegate to the home teams the lead responsibility for negotiation of waivers and exclusions for requirements in potential host countries.

\subsection{National Environmental Policy Act Considerations}

A major regulatory requirement to be addressed for ITER is the environmental impact issue, which derives from the National Environmental Protection Act of 1969 (NEPA 1969). A summary illustration of the NEPA process is presented in Figure 2. The right side of the figure indicates the documents produced from the process. As shown in the figure, the public has many opportunities for interaction and input during the process.

The Notice of Intent (NOI) and its comment period provide information to the scoping or planning phase of the process. The scoping phase is designed to identify public and agency concerns, define the issues and alternatives that will be examined in detail, ensure that the draft Environmental Impact Statement (EIS) addresses the issues, and develop a plan for EIS preparation.

The public and agency comments obtained during the comment period will be used by DOE and the JCT to identify major issues and to define the final alternatives that will be evaluated in the EIS. The results of this phase will be reflected in an Implementation Plan for the draft EIS. The EIS will report the necessary background data and the analyses needed to help decision makers understand the potential environmental consequences of each of the alternatives identified for implementation of the siting, construction, and operation of ITER. 


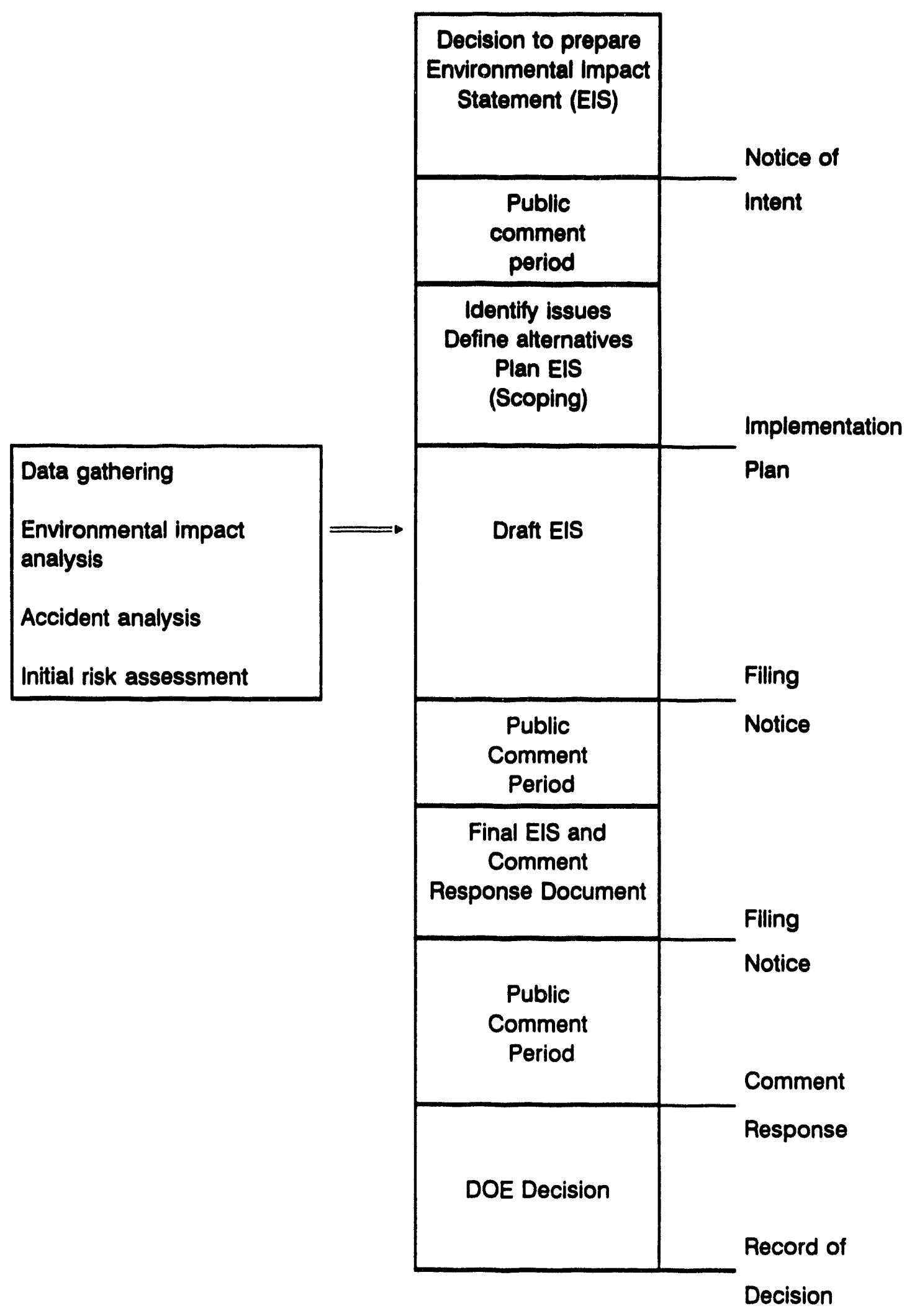

Figure 2. National Environmental Policy Act (NEPA) process. 
DOE Office of Fusion Energy (DOE-OFE) will be the primary JCT interface for the ITER environmental compliance actions in the U.S. The specific responsibilities and authorities of other DOE Headquarters and field personnel for implementation of the NEPA assessment process are stated in DOE 5440.1E Additional guidance is also provided in DOE 4700.1.

The EIS deals with operational environmental issues by defining the environmental impacts of the project, but it also provides the initial facility accident consequence analysis. The current trend in DOE is toward increasing the level of sophistication in the accident consequence analysis in the EIS, despite the lack of a detailed design. The Record of Decision (ROD) is prepared and published by DOE after completion of the final EIS. The ROD states DOE's decision for the courses of action described in the EIS. The accident consequence analysis information in the EIS is one part of the baseline that contributes to more detailed safety analyses. These analyses will be documented in the facility preliminary safety analysis report (PSAR) and ultimately in the FSAR. Compliance with NEPA will be required by the U.S. for ITER regardless of the host country because of DOE's large financial involvement in the program.

DOE 4700.1 outlines the phased environmental compliance requirements for a DOE project from initiation of the project through issuance of approval to operate. Figure 3 presents a bar chart of the compliance requirements along with the overall project activities. The figure includes activity nodes for the Draft Environmental Impact Statement (DEIS) and the Final Environmental Impact Statement (FEIS). The ROD on the EIS alternatives must be made before the detailed design can begin.

\subsection{Design}

This section discusses the aspects of the design phase that affect the regulatory approval process. Although the design phase for a DOE facility is one of the most important life-cycle phases, its impact on the overall regulatory process is more tactical than strategic. Some subphases of the design process are hold points for approval actions by interfacing organizations. Many design-related activities are crucial to the overall regulatory approval process. However, the actual design process itself is not critical to the overall JCT strategy for regulatory approval planning. The design phase significantly overlaps with both the safety analysis and construction phases, and it also overlaps the operation phase, particularly during facility modifications. These schedule characteristics are significant to scheduling the subphases of the facility life-cycle, but not to the overall strategic planning for regulatory approval.

This report does not provide a detailed description of the design phase. More detailed identification of specific tasks, products, and interface issues would be discussed in the baseline plan, described in Section 2.1. However, major project key decisions for acquiring a major DOE system (DOE 4700.1) must be considered by the JCT in establishing the milestones in the ITER regulatory approval plan. These key decisions will be identified in the development of the baseline requirements, assessed to determine their applicability to this activity, and integrated into the overall ITER Project Plan. 


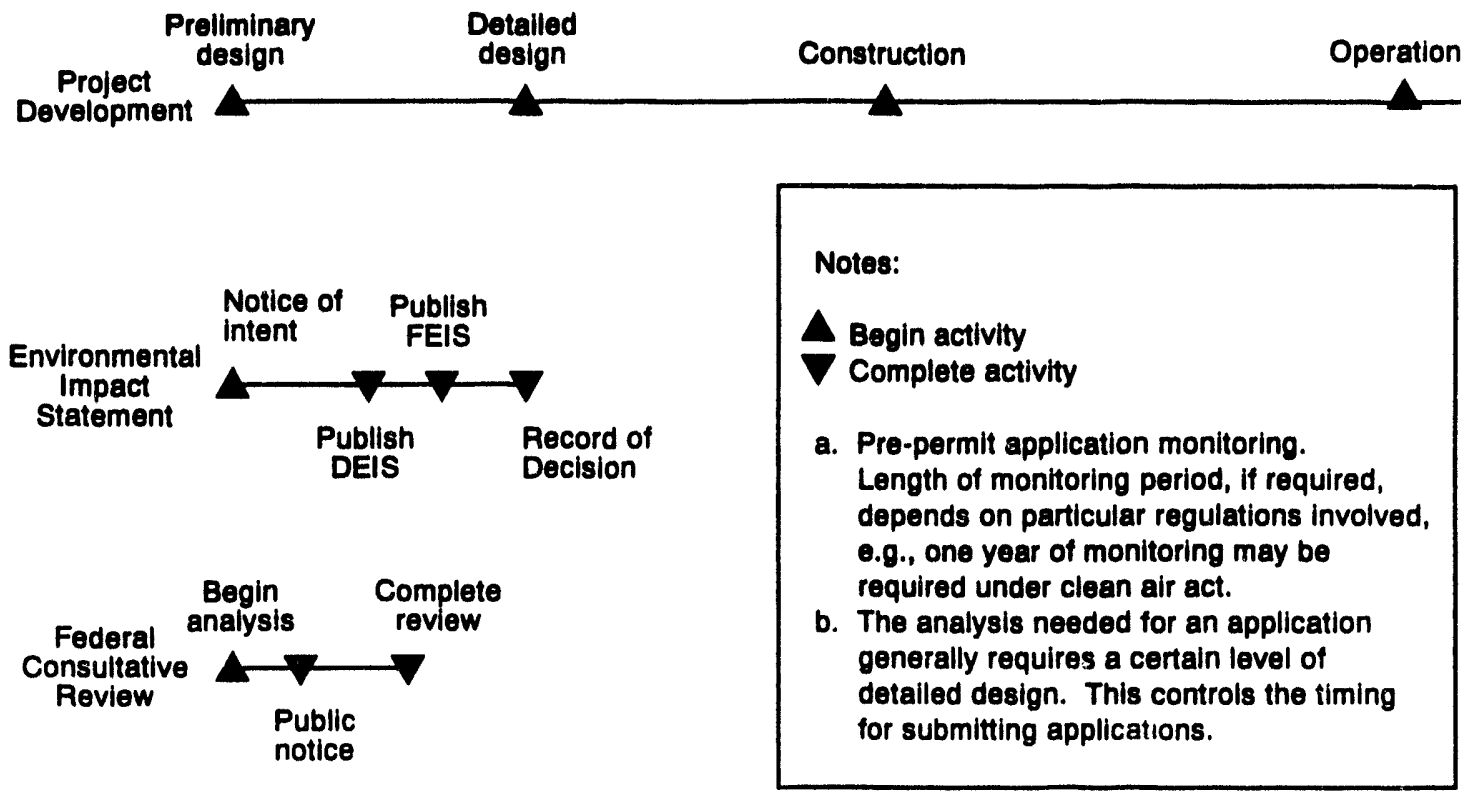

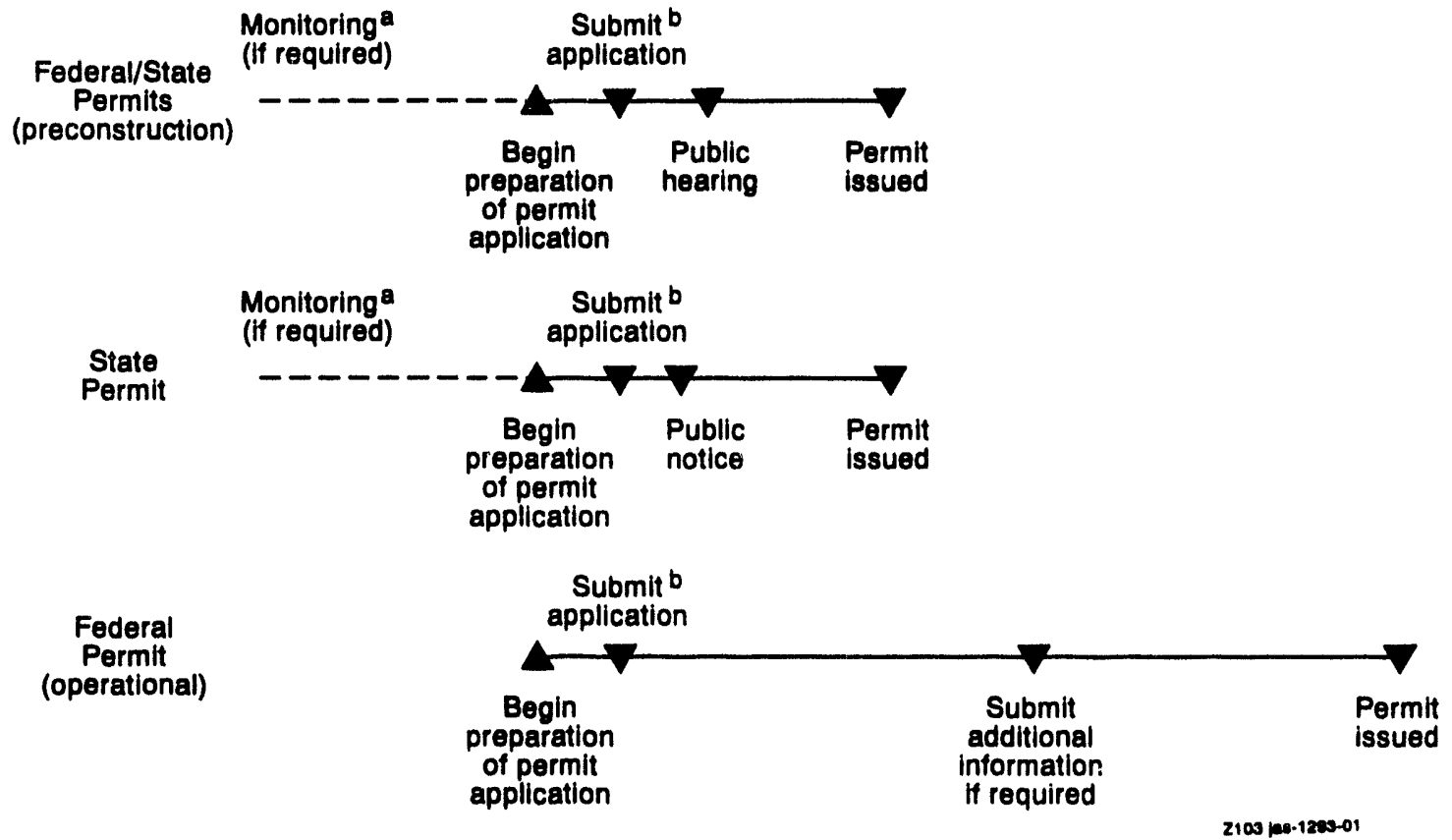

Figure 3. Project time line for compliance with environmental requirements. 
The key decisions are an integral part of the DOE funding decisions. However, they may or may not integrate directly and individually into the ITER planning. Key Decision 0 is Approval of Mission Need. This statement is a prerequisite for requesting conceptual design funding and for release of appropriated funding. Key Decision 1 is Approval of New Start. It is a prerequisite for requesting project line item (design) funding. Key Decision 2 is Approval to Commence Title II, or Final or Detailed Design. One of the required inputs to this decision is the completion of Title I, Preliminary Design. Key Decision 3 is Approval to Commence Construction. And Key Decision 4 is Approval to Commence Operation, a decision that is not made until the capability is demonstrated to meet the technical performance goals specified in the project baseline, which was approved in Key Decision 1.

The design phase encompasses many specific activities and produces many documents, which are directly relevant to the ultimate approval-to-operate decision and are used in the design reviews, independent nuclear safety reviews, and operational readiness reviews. The activities include Title I and II design, analyses, trade-off studies, and make-buy reviews. The activities generate product documents, such as drawings, design study reports, analysis reports, and procurement documents. A knowledgeable, detailed, thorough consideration of each of these processes in the baseline requirements document will enhance the ITER planning.

Some technical issues discussed in Section 4 are related to the design function and will be mentioned in this section. Some are essentially design in nature, such as the safety class items; some affect the design process, such as quality assurance; and others, such as emergency planning, result in the imposition of demands or requirements on the design function. All are significant issues that must be addressed to structure the overall ITER regulatory approval framework. However, individually they do not constitute strategic issues in the design phase.

One additional technical issue is waste management during operation, decontamination, and decommissioning. Producing less waste should be a guiding principle for ITER during all phases of its life cycle. Adoption of this principle will have a major effect on design activities, especially materials selection decisions.

\subsection{Safety Analysis}

Safety analysis is probably the most significant phase for a DOE nuclear facility in terms of the impact on the ultimate receipt of regulatory approval to operate the facility. DOE requirements for activities during the safety analysis phase are stated in several DOE orders and standards (DOE 5480.5, DOE 5480.22, DOE 5480.23, DOE 5481.1B, DOE STD 1027, and DOE STD 3009). The safety analysis phase encompasses the following activities:

- Descriptive identification of the specific facility or activity

- Identification and quantification of each specific hazard in the facility and the maximum expected facility hazard

- Designation of a DOE facility hazard category based on the estimated risk of consequences from unmitigated hazards 
- Preparation of a PSAR and FSAR

- Preparation of technical safety requirements (TSRs)

- Completion of the associated reviews by the operating contractor and the DOE.

ITER is the descriptive identification of the specific subject facility; however, at the time the DOE regulatory approval process is formally initiated, documentation will be required to establish the physical bounds of the facility and the activity. Descriptions will be required of systems, buildings, processes, and support services that make up the project seeking approval.

DOE uses the identification and quantification of the maximum expected and allowed inventory of hazardous materials to determine whether the facility is nuclear or nonnuclear. ITER is currently being addressed as a nonreactor nuclear facility by most of the fusion community. The final determination of the maximum quantities of hazardous material will form the basis to formally affirm the categorization of ITER as a nuclear facility. The designation of the DOE Hazard Category 1, 2, or 3 is based on a risk consequence conclusion. The hazard analysis will show the potential for only significant local consequences from unmitigated hazards, Category 3; significant onsite consequences, Category 2; or significant offsite consequences, Category 1. In the case of ITER, the hazard assessment process described in Attachment 1 of DOE STD 1027 would not only affirm the nuclear designation that has unofficially been given to ITER but also establish the DOE hazard category.

Two actions regarding safety analysis reports warrant highlighting in this overview of the DOE regulatory approval process. First, DOE approval of the PSAR is required (DOE 5480.23) "prior to undertaking procurement of materials and components, construction, and pre-operational testing of DOE nuclear facilities." Second, the operating contractor of a DOE nuclear facility is required (DOE 5480.23) to submit an FSAR for DOE approval before DOE authorizes the facility to operate. This authorization is the ultimate goal of the entire DOE regulatory approval process. DOE requires that the FSAR document the adequacy of the safety basis and provide assurance that the facility can be operated, maintained, and shut down safely. The FSAR also shows compliance with applicable laws and regulations. Again, the nature of the DOE requirements emphasize the importance of professionalism in the development of the baseline requirement documentation.

TSRs (DOE 5480.22) are derived from the SAR and describe the safety envelope within which the facility will be contractually operated. The TSRs must be completed at the same time as the FSAR, and they must be submitted as supporting documentation for the request for approval to operate.

The safety analysis phase has several reviews. One of the most important, the Operational Readiness Review (ORR) (DOE 5480.31), is cited here because of its unique importance in the regulatory approval sequence. The $O R R$ is the final assessment of operational readiness by the contractor and DOE. As such, the review can enhance the contractor's credibility if the preparation for it is professionally managed through all preceding phases of the facility life cycle. DOE 5480.31 describes the requirement for completion and documentation of an ORR before 
DOE issues approval to operate a new or modified facility. A contractor-performed ORR is a prerequisite for the DOE Operational Readiness Review. The ORR process can take up to a year, even with careful preparation during all pre-operational phases.

More detailed discussions of the SAR content, the hazard classification process, and the application of the graded approach concept in safety analyses are presented in Section 4. Again, the details presented are not necessarily germane to the structuring of the ITER regulatory approval framework but are provided for information to the JCT.

\subsection{Construction}

While the construction phase of a nuclear facility affects the project in terms of schedule, cost, and mission success, only two construction phase activities impact the top-level concerns that are directly relevant to obtaining DOE regulatory approval. Management planning is essential prerequisite for quality assurance (QA) and configuration management. Quality assurance and control are especially important nuclear safety related activities during construction. Configuration management remains an important activity from construction through decommissioning because of the change order system implicit in construction activities. Both of these issues should be addressed as elements in baseline requirements planning.

The comprehensive documentation of baseline requirements, as described in Section 2.1, should identify all construction-oriented activities that are even marginally relevant to the ITER regulatory approval. Therefore, the DOE project management plan order (DOE 4700.1) provides constructive guidance for the overall management of DOE construction activities.

\subsection{Operation}

As with the design and construction phases, few operational requirements directly impact the primary thrust of the DOE regulatory approval process. DOE has developed a comprehensive set of requirement guidelines in the conduct of operations order (DOE 5480.19), which must be addressed in the development of the baseline requirements document. The graded approach concept (DOE RULES), which applies to virtually all DOE nuclear safety standards, orders, and directives, is relevant to the 18 subject areas addressed in the conduct of operations order. The order reflects good management practices that have evolved from the nuclear industry, DOE, and contractor experience in a variety of nuclear facilities. However, the JCT must manage the review, assessment, and adoption of the guidance elements in the conduct of operations order for fusion operating needs. The early negotiation of exclusions, additions, and modifications to this operations directive to make it relevant to fusion will contribute to the crispness of the ITER regulatory approval process. At all stages of the facility life cycle (especially at the review and key decision nodes), planning, advanced preparation, and negotiation will far outweigh the cost of the resources expended.

Several activities in the operations phase warrant discussion to ensure they are not forgotten in the baseline development activities. These activities include facility modifications that involve reviewing the requirements for design, construction, and safety analysis; integrated plant testing that is sometimes considered as the final stage of the design and construction phase; inservice 
inspection, which is an integral part of the maintenance function in operations; processing of unreviewed safety questions (DOE 5480.21); changes to the SAR; and changes to experiments and experimental programs.

\subsection{Decommissioning}

The final phase in a DOE facility life cycle is decontamination and decommissioning (D\&D). D\&D contains elements that affect the overall regulatory approval process. The DOE requirements regarding decommissioning are stated in DOE $5820.2 \mathrm{~A}$

The most salient decommissioning requirement for long-range facility planning, which is the responsibility of the JCT for ITER, is knowledge of the DOE policy, which reads as follows: "Radioactively contaminated facilities for which DOE is responsible shall be managed in a s.ufe, cost-effective manner to ensure that release of and exposure to, radioactivity and other hazardous materials comply with Federal and State standards. Facilities, equipment, and valuable materials shall be recovered and reused when practical." Accordingly, this policy must be incorporated into the requirements planning and the design from the outset of the ITER planning process. Specific requirements in the decommissioning order that must be integrated into ITER involve design, operational records, surveillance, hazardous materials records, waste records, environmental concerns, and the entire NEPA process. Ultimately, the D\&D task will be managed under the DOE project management policy (DOE 4700.1). The task will include its own environmental review process and will have several product documents, such as a decommissioning plan, project data package that includes a record of completion, and a final radiological and chemical survey report.

Completeness and professionalism in the preparation of the baseline requirements for the D\&D phase will contribute to an efficient and effective regulatory approval process for ITER. In addition, the disciplined management of the baseline requirements for D\&D in other phases of the facility life cycle will contribute significantly to successful decommissioning the facility.

Waste management is significant during D\&D. It is also a major operational requirement throughout the life of the ITER. Therefore, the baseline requirements developers must address both the on-going operational waste management requirements (e.g., a waste minimization policy) and the D\&D waste management requirements. The final ITER design, its construction materials, and its operational and test program, will determine the waste product analyses. The options for waste disposal and management will have to be identified. Currently, many waste remediation activities are being conducted throughout the world. These activities will significantly affect fusion. Precedent-making decisions are being made about the nature of waste materials, the masses of materials, the activity types and levels, and the disposal options. Therefore, the fusion community : hould participate in the waste management decision making processes to ensure that fusion s needs are represented. 


\section{RADIOLOGICAL AND BERYLLIUM SAFETY CRITERIA}

A significant part of the DOE regulatory system is based on protecting the workers, public, and the environment from the risks of exposure to radiation. Many of the detailed regulatory requirements are based on radiation dose limits to workers, the public, and the environment. The applicable DOE orders specifically implement radiation protection standards that are generally consistent with those used by the Nuclear Regulatory Commission (NRC) and those recommended by knowledgeable organizations such as the International Commission on Radiological Protection (ICRP). In setting these criteria, the DOE tries to maintain potential radiation exposures to the public as low as reasonably achievable (ALARA) and at the same time monitors DOE facilities for routine and nonroutine releases. The purpose of this section is to summarize the general radiological criteria being used by DOE to regulate operations at its DOEowned contractor-operated facilities. The section also includes a discussion of U.S. criteria related to beryllium exposure, because of its potential use in ITER.

\subsection{Normal Operating Releases}

DOE 5400.5 states that the exposure to members of the public to radiation sources as a consequence of all routine DOE operations shall not cause in a year an effective dose equivalent to the maximum exposed individual greater than $1 \mathrm{mSv}(100 \mathrm{mrem})$ based on all exposure pathways. Additionally, the order states that DOE facilities will abide by EPA orders relating to specific sources and exposure pathways. For airborne emissions, the EPA regulations in 40 CFR 61 limit the exposure of members of the public to airborne emissions from DOE operations to less than $0.1 \mathrm{mSv}(10 \mathrm{mrem})$ in a year. For exposure from high level nuclear waste at a DOE facility, 40 CFR 191 requires that annual exposures to the public in the general environment resulting from discharges or radioactive material and direct radiation be less than $0.25 \mathrm{mSv}$ ( $25 \mathrm{mrem}$ ) dose equivalent to the whole body and less than $0.75 \mathrm{mSv}$ ( $75 \mathrm{mrem}$ ) committed dose equivalent to any organ. Finally, DOE 5400.5 requires that DOE provide a level of protection for persons consuming water from a public drinking water supply operated by DOE equivalent to public community drinking water standards as set forth in 40 CFR 141. This requirement translates into an effective dose equivalent of $0.04 \mathrm{mSv}(4 \mathrm{mrem})$ in a year. Based on these requirements, derived concentration guides for air and water were developed for a variety of radionuclides and are attached as an appendix to DOE 5400.5.

In all these cases, the values represent DOE regulatory limits. DOE 6430.1A indicates that design goals should be established for each facility to contain releases of hazardous material in accordance with the ALARA principle. Thus, the established design basis release limits shall be less than the regulatory requirements.

\subsection{Worker Dose Limits}

Under DOE 5480.11, the radiological workers at DOE facilities are limited to an annual effective dose equivalent (internal and external) exposure of $50 \mathrm{mSv}(5 \mathrm{rem})$. Exposures to organs, tissues, or extremities are limited to $500 \mathrm{mSv}$ (50 rem). Lower limits apply to declared pregnant women, minors (less than 18 years old) and students, visitors, and the public. Higher 
exposures are tolerated for emergency situations, such as saving a human life, recovering a deceased victim, and protecting health and property.

DOE has adopted an ALARA policy with respect to worker exposure. Consequently, DOE operations offices and contractors are encouraged to establish lower exposure goals where possible. An administrative goal of $15 \mathrm{mSv}$ (1.5 rem) per year has been established for each facility at the Idaho National Engineering Laboratory (INEL) by the DOE Idaho Operations Office. EG\&G Idaho, the prime contractor at the INEL, has established an administrative goal of $5 \mathrm{mSv}(500 \mathrm{mrem}$ ) per year for personnel working at the facilities (EG\&G 1992). Proper facility design and control (e.g., confinement, ventilation, remote handling, and shielding) are the primary means of maintaining radiation exposures as low as reasonably achievable. Administrative and procedural requirements are considered as supplementary means to achieve control.

\subsection{Accident Releases}

DOE 6430.1A provides radiological siting guidelines for nonreactor nuclear facilities. ITER appears to meet the DOE definition of nonreactor nuclear facility. The order states that the maximum calculated dose to an offsite individual from exposure that results from internal and external sources of radiation must not exceed $250 \mathrm{mSv}(25 \mathrm{rem}) 50$-year committed dose equivalent to the whole body. For other organs of the body, the 50 -year committed dose equivalent limits are $3 \mathrm{~Sv}(300 \mathrm{rem})$ to the thyroid, $3 \mathrm{~Sv}(300 \mathrm{rem})$ to the bone surface, $750 \mathrm{mSv}$ ( $75 \mathrm{rem})$ to the lung, and $1.5 \mathrm{~Sv}(150 \mathrm{rem})$ to any other organ. If multiple organs receive doses during the same exposure, the effective dose equivalent shall not exceed $250 \mathrm{mSv}(25 \mathrm{rem})$. The exposure duration is generally 2 hours in keeping with fission practice for estimates of prompt dose. However, we recognize that a 7-day exposure to determine early dose is more in keeping with recent international fusion safety assessments. DOE 6430.1A recommends using meteorological conditions that result in unfavorable dispersion (e.g., the higher of the $0.5 \% \times / \mathrm{Q}$ for each sector of the site and the 5\% direction independent $x / Q$ for the site). In the absence of a site, conservative meteorology (Class $F, 4.5 \mathrm{~m} / \mathrm{s}$ wind speed) should be used for design assessments.

The order notes that these values are guidelines and do not constitute acceptable limits on the doses to the public in the event of an accident. These guidelines are used by DOE to evaluate the design of the facility in combination with the site characterization with respect to the risk to the public from low probability accidents. Accidents to be evaluated for comparison to these dose guidelines include events with an annual probability of occurrence greater than $10^{-6}$. When the doses are calculated, the degraded performance of engineered safety features and administrative controls shall be assumed unless they can be shown to be capable of performing their safety function. Accidents with probabilities lower than $10^{-6}$ must be evaluated in the SAR (DOE 5480.23). However, no dose limits have been identified for these events.

In addition to the radiological siting guidance in DOE 6430.1A, DOE has issued radiological consequence guidelines for nonreactor nuclear facilities (Brynda 1986) to ensure that nonreactor nuclear facilities are designed so they can be operated without undue risk to the general public or workers at the facility. These guidelines require that doses resulting from normal operation be maintained as low as reasonably achievable and that allowable doses from off-normal and accident 
conditions be scaled as a function of the probability of occurrence of the initiating event. Table 1 lists the guidelines for offsite doses:

Table 1. Guidelines for offsite doses.

\begin{tabular}{|c|c|c|}
\hline Description of Event & Probability of Occurrence & Dose Guideline \\
\hline $\begin{array}{l}\text { Normal and Anticipated Events } \\
\text { Unlikely Event } \\
\text { Extremely Unlikely Event } \\
\text { Incredible Events }\end{array}$ & $\begin{array}{l}10^{-2} \leq P \leq 1 \\
10^{-4} \leq P \leq 10^{-2} \\
10^{-6} \leq P \leq 10^{-4} \\
P \leq 10^{-6}\end{array}$ & $\begin{array}{l}1-5 \mathrm{mSv} \\
5-25 \mathrm{mSv} \\
25-250 \mathrm{mSv} \\
>250 \mathrm{mSv}\end{array}$ \\
\hline
\end{tabular}

\subsection{Emergency Planning Criteria}

The DOE 5500 series of orders present the DOE emergency planning and management system, including classification of emergency events, notification and reporting requirements, and planning and preparedness requirements. These orders consider events or incidents resulting in both nonradiological and radiological releases at levels that could represent a hazard to the public. For nonradiological releases, emergency planning response guidelines developed and approved by the American Industrial Hygiene Association are used for DOE planning. For radiological releases, the EPA is responsible for providing criteria to use in planning protective actions for radiologica! emergencies.

The EPA uses the concept of a projected dose as a criterion to judge the potential risk to the public in the event of a nuclear incident (EPA 1975). The projected dose is an estimate of the amount of radiation that the affected population may receive after a nuclear incident. Protective action guidelines (PAGs) are numerical projected doses to individuals in a population. The PAGs act as trigger points to initiate protective action. These guidelines do not imply an acceptable dose, but are used as a means of reducing risk to the public.

The EPA has broken down an incident into three phases with protective actions appropriate for each. The phases defined by duration are (a) early (hours to days), (b) intermediate (weeks to months) and (c) late or recovery phase (typically months to years). For the early phase, the appropriate protective actions are evacuation or sheltering to protect the public from direct radiation and inhalation from the airborne plume. In the intermediate phase, the distribution of food must be stopped or controlled to protect the public from ingesting contaminated items. In the recovery phase, the protective action is relocation, decontamination, or both to avoid wholebody external exposure from deposited radioactive material and inhaled radionuclides. The PAGs or projected doses that trigger protective actions for each phase are shown in Table 2, along with comments that explain the specific type of dose that must be calculated. Additional information on emergency planning requirements is located in Section 4.8 . 
Table 3. Waste classifications, classes, and disposal methods.

\begin{tabular}{|c|c|c|}
\hline $\begin{array}{c}\text { Waste } \\
\text { classification }\end{array}$ & Definition & Disposal method and requirements \\
\hline $\begin{array}{l}\text { Greater than } \\
\text { Class C }\end{array}$ & $\begin{array}{l}\text { Does not qualify for near-surface } \\
\text { disposal. Proposed disposal methods } \\
\text { are considered case by case. }\end{array}$ & $\begin{array}{l}\text { Form and disposal method more stringent } \\
\text { than Class C. Deep geological burial. }\end{array}$ \\
\hline $\begin{array}{l}\text { Class C } \\
\text { Intruder } \\
\text { Waste }\end{array}$ & $\begin{array}{l}\text { Does not decay to safe level in } 100 \\
\text { years. Decays to acceptably safe level } \\
\text { in } 500 \text { years. }\end{array}$ & $\begin{array}{l}\text { Minimum packaging. Stability for } \\
500 \text { years. Protect against inadvertent } \\
\text { intruder. Bury } 5 \mathrm{~m} \text { below surface with } \\
\text { natural or engineering barrier. }\end{array}$ \\
\hline $\begin{array}{l}\text { Class B } \\
\text { Stable Waste }\end{array}$ & $\begin{array}{l}\text { Stabilized and decays to levels that do } \\
\text { not pose a danger to public health } \\
\text { and safety in } 100 \text { years. }\end{array}$ & $\begin{array}{l}\text { Minimum packaging. Stability for } \\
300 \text { years. Near surface burial. Covered } \\
\text { to reduce surface radiation to a few } \\
\text { percent of natural background. }\end{array}$ \\
\hline $\begin{array}{l}\text { Class A } \\
\text { Segregated } \\
\text { Waste }\end{array}$ & $\begin{array}{l}\text { Decays to acceptable leveis during } \\
\text { site occupancy. }\end{array}$ & $\begin{array}{l}\text { Segregated. Minimum packaging. } \\
\text { Near-surface burial. }\end{array}$ \\
\hline
\end{tabular}

postulated accidents at the waste disposal site. The exposure must be less than $5 \mathrm{mSv}(0.5 \mathrm{rem})$ in the first year for the waste to classify as Class $\mathrm{C}$ waste. The risk-dominant accident scenario for a waste site is that of the exposure of an inadvertent intruder to the disposal site after the period of institutional control (100 years) ends. Thus, 10 CFR 61 sets specific activity limits for Class $\mathrm{C}$ waste based on the 50 -year whole body dose commitment from long-lived radionuclides so that the inadvertent intruder dose is less than $5 \mathrm{mSv}(0.5 \mathrm{rem})$ during the first year. Class $\mathrm{C}$ waste must be disposed of $5 \mathrm{~m}$ below the surface with natural or engineered intruder barriers, such as concrete covers, to minimize the potential for intruder disturbance of the waste.

Wastes with specific activities greater than the Class $\mathrm{C}$ limits are not suitable for near-surface burial and require deep geological burial in a form that is more stringent than Class $\mathrm{C}$ (e.g., vitrification in glass).

Finally, for Class B and C wastes, there are no limits on short-lived radionuclides whose impact on the dose to the inadvertent intruder is small. However, 10 CFR 61 indicates that practical considerations such as external radiation field and internal heat generation in transportation, handling, and disposal will limit the concentrations of these radionuclides (i.e., ${ }^{60} \mathrm{Co}$ and ${ }^{63} \mathrm{Ni}$ ). Currently, no regulatory approved limits on external radiation field and internal heat generation exist in the United States. However, work has been done by U.S. fission researchers (Kocher and Croft 1987) to propose such criteria in an attempt to develop an intermediate waste classification. They propose a decay heat limit of $50 \mathrm{~W} / \mathrm{m}^{3}$ and a dose rate of $1 \mathrm{~Sv} / \mathrm{hr}(100 \mathrm{rem} / \mathrm{hr})$ at $1 \mathrm{~m}$.

The U.S. waste classification is based largely on radionuclides that are important in fission facilities. Long-lived isotopes include ${ }^{14} \mathrm{C},{ }^{59} \mathrm{Ni},{ }^{94} \mathrm{Nb},{ }^{99} \mathrm{Tc},{ }^{129} \mathrm{I},{ }^{241} \mathrm{Pu},{ }^{242} \mathrm{Cm}$, and all other 
alpha-emitting transuranics with half-lives greater than 5 years. Tritium, ${ }^{60} \mathrm{Co},{ }^{63} \mathrm{Ni},{ }^{90} \mathrm{Sr},{ }^{137} \mathrm{Cs}$, and all other nuclides with half-lives less than 5 years constitute the short-lived isotopes considered. In general, for fusion the isotopes are different because of the different materials being considered and the different transmutation products that are generated. Fetter et al 1990 have performed calculations to determine the Class $\mathrm{C}$ specific activity limits for all long-lived radionuclides using a methodology similar to that used in 10 CFR 61. Although the calculations carry no regulatory acceptance, they are useful because they include fusion-specific isotopes.

\subsection{Summary of Radiological Criteria}

A summary of the radiological criteria presented in this section is presented in Table 4 for ease of comparison.

Table 4. Summary of U.S. radiological criteria.

\begin{tabular}{|c|c|c|}
\hline Exposure type & $\begin{array}{l}\text { Dose limit } \\
\text { (EDE) }\end{array}$ & Comments \\
\hline $\begin{array}{l}\text { Normal operating } \\
\text { releases }\end{array}$ & $\begin{array}{l}<1 \mathrm{mSv} / \mathrm{yr} \\
<0.1 \mathrm{mSv} / \mathrm{yr} \\
<0.04 \mathrm{mSv} / \mathrm{yr}\end{array}$ & $\begin{array}{l}\text { All pathways } \\
\text { Airborne } \\
\text { Drinking water }\end{array}$ \\
\hline Worker doses & $\begin{array}{l}50 \mathrm{mSv} \\
500 \mathrm{mSv} \text {-any organ } \\
5 \mathrm{mSv}\end{array}$ & $\begin{array}{l}\text { Limit } \\
\text { Limit } \\
\text { Typical ALARA goal }\end{array}$ \\
\hline Accident releases & $250 \mathrm{mSv}$ & Design guidelines \\
\hline $\begin{array}{l}\text { EPA protective } \\
\text { action guidelines }\end{array}$ & $10-50 \mathrm{mSv}$ & $\begin{array}{l}\text { EDE at which protective actions } \\
\text { are required to protect the public }\end{array}$ \\
\hline Nuclear waste & $5 \mathrm{mSv}$ & $\begin{array}{l}\text { Exposure in first year to the } \\
\text { inadvertent intruder }\end{array}$ \\
\hline
\end{tabular}

\subsection{Beryllium Exposure Limits}

Beryllium and beryllium compounds can pose potential health risks to humans. Because of their potential use in the ITER EDA design, this section summarizes the current U.S. regulations about allowable emission to the environment and permissible occupational exposure to workers. Results presented here were obtained from the Syracuse Research Corporation (1991). Their report cited the primary sources in the following paragraphs.

The EPA has set limits on the emissions of beryllium into the environment from industries that process beryllium ores, metal, oxide, alloys, or waste. 40 CFR 61 limits the amount of beryllium emitted to $10 \mathrm{~g}$ in a 24-hour period or to an amount that would result in atmospheric levels of $0.01 \mu \mathrm{g} \mathrm{Be} / \mathrm{m}^{3}$ of air, averaged over a 30-day period. EPA's Office of Water Regulations and Standards limits the concentration of beryllium in water to between 0.68 and $68 \mathrm{ng} / \mathrm{L}$ for protection of human health. Higher levels are allowed for aquatic organisms. 
OSHA has established a time-weighted average permissible exposure limit of $0.002 \mathrm{mg} / \mathrm{m}^{3}$ for the Be concentration in workroom air. For short-term exposure (i.e, 30 minutes), the exposure limit is $0.005 \mathrm{mg} / \mathrm{m}^{3}$. These values are regulations that must be met. The National Institute of Occupational Safety and Health (NIOSH) recommends an exposure guidelines of $0.5 \mu \mathrm{g} / \mathrm{m}^{3}$ in workroom air during an 8-hour shift. There are also limits on acceptable Be ambient air concentrations and drinking water quality standards for a number of states in the U.S. (Syracuse Research Corporation 1991). 


\section{NUCLEAR SAFETY-RELATED TECHNICAL ISSUES}

This section provides some in-depth discussion of a selected list of nuclear safety-related technical issues to increase the awareness of the fusion community about these issues and their relevance to the overall regulatory approval process for ITER. We use the term "issue" somewhat guardedly in this report, recognizing that it can have very specific connotations to certain regulatory bodies. Our intent is to connote weak spots, soft spots, or potential inadequacies that need to be considered in ITER project planning.

The review of DOE standards, orders, and directives conducted as part of the development of DOE 5480.FUSION and associated guidance drafts (Reilly 1993) indicates that a number of nuclear safety-related technical issues need to be addressed in more depth for ITER than has been the case in the history of the fusion community. In some cases, either the fusion community has not been aware of the importance of the issue, or the issue has not yet been adequately considered in the ITER planning. Some are not adequately reflected in the R\&D planning that has taken place, and others are not adequately reflected in the design requirements that exist for ITER.

These nuclear safety-related issues need to be addressed by the ITER project early in the EDA to develop a credible case for obtaining regulatory approval in the U.S. None of these requirements are unique to fusion. Many are issues that must be dealt with in the management of any technological activity. Some are concerns only to facilities with nuclear safety-related hazards. But because of the high level of decay heat, activation products, and tritium in ITER compared with existing fusion experiments, the following issues may be perceived as relatively new to the fusion community:

- Safety analysis requirements

- The level of overall quality assurance required for the project

- Definition of safety class items for ITER, the associated design standards, and the level of testing required to qualify such items

- Verification and validation of computer codes

- Experimental databases needed for regulatory approval

- Level of technical understanding

- Tritium accountability

- Emergency planning.

Many of these issues will impact both the design and R\&D programs in ITER and, as such, requirements should be developed early so that rework and its associated cost will be minimized. The following sections discuss these issues and, where appropriate, present ideas that might be used by the JCT as they develop a regulatory framework for ITER during the EDA phase. 
The above list represents an initial attempt at highlighting some of the important issues for ITER; as such, the list is recognized as not being sufficient or complete. The completion of a disciplined baseline requirements plan, as described in Section 2.1, and the planning and accomplishment of a similarly disciplined safety analysis for ITER, may well surface other issues of comparable importance.

\subsection{Safety Analysis, Ha: ard Classification, and the Graded Approach}

In the overview of the reguiatory approval process for ITER, the singular importance of the safety analysis phase was stressed (see Section 2.4). This discussion provides details on three elements of the overall safety analysis phase for a DOE nuclear facility that should be given special attention as soon as possible in the ITER planning to prevent rework and to enhance cost effectiveness in the ITER project. The three elements are the SAR, the DOE hazard classification process, and the graded approach criterion that DOE has adopted. This material is intended to assist the JCT in structuring an efficient and effective approach to managing the regulatory approval process for ITER.

Definitions of key terms used with respect to safety analysis are based on DOE nuclear safety analysis and equipment qualification orders (DOE 5480.23, 6430.1A, and 5480.EQ). For more precise communication in this discussion, definitions have been taken from the orders for design basis, design basis accident, beyond design basis accidents, safety analysis, safety basis, safety class items, safety function, and technical safety requirements. These definitions are located in the Definitions at the beginning of the document.

\subsubsection{Purpose of the Safety Analysis}

Under DOE 5480.23, Nuclear Safety Analysis Reports, a contractor who is responsible for the design, construction, or operation of a DOE nuclear facility shall be required to perform a safety analysis. There are four major purposes for the safety analysis:

- Provide the basis for approval of new facilities and operations, major modifications, and eventual decommissioning

- Define and control the safety basis and commitments for design, procurement, construction, and operation to assure safety at the facility

- Support DOE, contractor management, and safety oversight of the facility

- Provide analytic rationale for operations as delineated in the Technical Safety Requirements (TSRs).

The preliminary safety analysis report (PSAR) serves as the principal safety basis upon which DOE makes a decision to authorize procurement, design, construction, and pre-operational testing activities. Its approval signifies that DOE understands the risks that are being assumed with facility operation. However, DOE may authorize in writing limited activities without approval of the PSAR. The final safety analysis report (FSAR) contains the final basis for safety and risk acceptance for the final design and serves as the basis for DOE to authorize facility 
operation The FSAR will include the operating envelope defined by the TSRs, safety design bases, cornmitments to applications of codes and standards, facility management controls, and institutional and human factors safety. It is a key means for sustaining operational authorization, risk management, and safety oversight. In some cases, a combined PSAR/FSAR would be acceptable, but that would not be expected to be the case for a major system acquisition with the complexity of TTER.

The safety analysis report (SAR) should define the safety basis, document the logic of its derivation, demonstrate adherence to the safety basis and justify its adequacy, as well as provide thorough documentation of the assumptions employed in the safety analysis. The safety analysis must identify the dominant contributors to the risk of the facility so that these vulnerabilities can be better managed. The SAR for a DOE facility is also expected to be a living document that is updated annually to reflect changes in design and operation. This approach offers a means by which the safety basis remains valid, so that the acceptability of the safety of the facility can be adequately judged.

The order also requires that a graded approach (see definitions on Page xiii) be used to determine the level of safety analysis needed for the facility. The use of this graded approach is intended to allow DOE a mechanism to allocate resources for safety assessment relative to the overall risk associated with operating the facility.

\subsubsection{Hazard Classification}

One of the initial steps in the safety analysis process is the performance of a preliminary assessment of the magnitude of the hazards of a facility. DOE STD 1027 provides a means of categorizing a nuclear facility based on the potential dose to the public as indicated by the inventory of radionuclides in the facility and its unmitigated release potential to the environment. Threshold quantities of each radionuclide are established and used to determine the hazard category. The three hazard category level numbers (Category 1,2, and 3 ) are inversely proportional to the actual risk consequence, Category 1 being the greatest. The categories are defined as follows:

- Category 1 - A facility in which the hazard analysis shows the potential for significant offsite consequences

- Category 2 - A facility in which the hazard analysis shows the potential for significant onsite consequences

- Category 3 - A facility in which the hazard analysis shows the potential for only significant localized consequences.

No numerical dose value is given in DOE STD 1027 to define the threshold for significant offsite consequences. The threshold for significant onsite consequences is defined as a committed effective dose equivalent of $10 \mathrm{mSv}(1 \mathrm{rem})$ at $100 \mathrm{~m}$ using a wind speed of $4.5 \mathrm{~m} / \mathrm{s}$ and Class D atmospheric stability for meteorological conditions. Significant localized consequences are defined as releases resulting in an effective whole body dose of $100 \mathrm{mSv}(10 \mathrm{rem})$ for one day of inhalation and direct exposure, $30 \mathrm{~m}$ from the point of release. If a facility has greater than 
$1,000 \mathrm{Ci}$ of tritium, it is a Category 3 facility ${ }^{\mathrm{b}}$, whereas a Category 2 facility has a tritium inventory greater than $3 \mathrm{MCi}$ of tritium. Similar inventories for many of the fusion activation products have not been developed because the standard is primarily for fission systems. An isotope listing for hazard classification that is appropriate for fusion is needed. In the DOE system, Category 1 facilities include the DOE Class A reactor facilities. An example of a Category 2 facility might be a uranium fuel manufacturing plant. TFTR is now a Category 3 facility because of the introduction of tritium into the facility.

The hazard categorization constitutes a method that addresses potential consequences but does not address risk (i.e., probability and consequence). In addition to this methodology, there are three other criteria that can be used in evaluating the hazard classification of a facility. They are:

- The complexity of the facility

- The potential energy sources in the facility

- Potential for offsite consequences, as judged by the DOE Program Secretarial Official (PSO).

DOE STD 1027 does not explicitly provide numerical guidance on what constitutes a Category 1 facility in terms of complexity, magnitude of the potential energy sources, or offsite consequence potential. This and other ambiguities and judgments regarding the hazard categorization of ITER underscore the need for the disciplined development of baseline requirements as soon as possible. This development must include the negotiation of exclusions, waivers, and clarification of ITER intent wherever there are specific deficiencies in the directives.

An appropriate list of bounding quantities of fusion isotopes will be needed to categorize the hazards for ITER if the general process required by DOE STD 1027 is to be implemented. It should also be kept in mind that the ITER complexity, which we judge to be greater than many fission reactors, the ITER potential energy sources (e.g., coolant stored energy and magnets), and its first-of-a-kind nature may all contribute a higher consequence categorization than that predicted based solely on inventories.

Hazard category levels are intended to provide gradation in the level of effort required to demonstrate compliance with DOE safety requirements. As such, they complement the graded approach concept advocated by DOE. But because DOE's graded approach concept is articulated in terms of general requirements rather than prescriptive norms, the approach to be taken in ITER to implement the graded approach concept will have to be to defined at a measurable level. In this regard, the fusion community will be breaking new ground because nowhere within DOE has there yet been a definitive measurable translation of the graded

b. The threshold value for tritium for a category 3 facility is based on recommendations from a U.S. tritium focus group and is not derived from the dose estimates in the standard as is the case for other radionuclides. 
approach concept that has contractor and customer acceptance. In addition, the new ground broken will constitute a precedent for future fusion activities.

Finally, fusion has a unique advantage over most fission technologies because the hazard, in terms of induced activation products in structure and tritium, can be minimized through prudent selection of materials. The U.S. magnetic fusion program has capitalized on this technical difference by pursuing a low activation materials program. The use of low activation materials in ITER would lower its intrinsic hazard, which would help in reducing the effort needed to obtain regulatory approval in the U.S. This approach also complements the DOE philosophy of hazard reduction at the source, which is a tenet of the DOE hazard categorization process.

\subsubsection{Contents of the Safety Analyala Report}

The basic content elements of an SAR are prescribed in DOE STD 1027 and DOE 5480.23 and are listed later in this section. However the owner-operator of a DOE facility is given some latitude in the depth of treatment of each of the elements. DOE STD 1027 states that "the graded approach dictates a more rigorous and more thoroughly documented analysis and evaluation of higher hazard facilities than lower hazard facilities, given the potential for more widespread and severe consequences if a higher hazard facility fails to meet its safety basis requirements." The order states that the greater the hazard, the "more penetrating, thorough, and well documented the SAR." Thus, the SAR for a Category 2 facility may not need to be as thorough and penetrating as a Category 1 facility SAR. Allocation and emphasis in the analysis and documentation should be proportional to the complexity for each subject area in the SAR, i.e., a graded approach should be reflected.

DOE STD 1027 provides guidance on the analytic techniques that are acceptable for accident analysis of Category 1,2, and 3 facilities. For category 3 facilities, limited effort is required to develop the key set of accidents and determine the consequences. The level and sophistication of the analysis increases for a category 2 facility. Probabilistic techniques such as event trees and fault trees are recommended to define the key accident sequences. Operational events, design basis events, natural phenomena, external events, and beyond design basis events must be considered in the accident identification stage. DOE 6430.1A states that consequences from internally initiated accidents with annual probabilities of occurrence greater than $10^{-6}$ be compared with accident radiological release guidelines (see Section 3). DOE 548028 on natural phenomena hazards mitigation provides guidelines on externally initiated accidents. External events with annual probabilities greater than $-2 \times 10^{-4}$ would be considered in the design basis for a facility like ITER. Thus, although not explicitly stated, it can be interpreted that the $10^{-6}$ frequency value defines the line between a design basis accident and a beyond design basis accident. More detailed engineering analysis is also required to determine the response of important safety systems, structures, and components during the accident than nonsafety class items. In addition, a detailed source term and dose assessment must be performed. The requirements for Category 2 facilities also apply to Category 1 facilities.

Although DOE 5480.23 recognizes that the SAR for Category 2 facilities need not be as thorough and penetrating as for Category 1 facilities, there appears to be ostensibly very little difference in the level of sophistication required in the safety analysis between a Category 1 and 2 facility, as presented in DOE STD 1027. The real difference is judged to be a matter of degree 
in terms of completeness and the burden of proof. The DOE orders specifically avoid the use of the word completeness in terms of the SAR, probably because even for a Category 1 facility it would be difficult and costly, if not impossible, to be complete. However, DOE 548023 does requires the SAR to be thorough and penetrating. This raises a key question for ITER: "When is the safety analysis sufficiently thorough and penetrating?" This is a difficult question to answer because there are no DOE criteria to measurably assess such a question. A criterion developed by one of the authors in conducting independent nuclear safety reviews of fission reactor documentation may have applicability here: Is the risk identified, is it quantified and is it accepted by the owner-operator with adequate technical basis? Adoption of this review concept by the incependent nuclear safety reviewers for ITER and its SARs, who presumably will have both fission and fusion experience, will help ensure that nothing has been overlooked or given inadequate attention.

DOE 5480.23 lists the following topics to be included in the SAR:

- Executive summary

- Applicable statutes, rules, regulations and DOE orders

- Site characteristics

- Facility description and operation, including design of principal structures, components, systems, engineered safety features, and processes

- Hazard analysis and classification of the facility

- Principal health and safety criteria

- Radioactive and hazardous material waste management

- Inadvertent criticality protection (not applicable to ITER)

- Radiation protection

- Hazardous material protection

- Analysis of normal, abnormal, and accident conditions, including

- Design basis accidents

- Assessment of risks

- Consideration of natural and man-made external events

- Assessment of contributory and casual events, mechanisms, and phenornena

- Evaluation of the need for an analysis of beyond-design-basis accidents (however, the SAR is to exclude acts of sabotage and other malevolent acts since these actions are covered under security protection to the facility).

- Management, organization, and institutional safety provisions 
- Procedures and training

- Human factors

- Initial testing, in-service surveillance, and maintenance

- Derivation of technical safety requirements (TSRs)

- Operational safety

- Quality assurance

- Emergency preparedness

- Provisions for decontamination and decommissioning

- Applicable Facility design codes and standards

- Facility unique features.

As detailed by this list, the SAR is quite broad in scope; however, varying degrees of emphasis may be placed on some of the SAR sections depending on the overall importance to the specific facility. The SAR is intended to be the central reference safety document that leads to other more detailed results. The guidance for DOE 5480.23 provides information on the details of each SAR section. This guidance is available in both DOE STD 1027 and DOE STD 3009. DOE offices are currently working on further guidance for producing SARs, including the SAR format and content for Category 2 and 3 facilities.

\subsection{Quality Assurance}

The level of effort and resources expended in the implementation of quality assurance in the fission nuclear industry is significantly more than in many industries and is notably more than has historically been the case for most fusion activities. Quality assurance has had a high priority for DOE facility management, and it is expected that this will be the case for ITER. Accordingly, this section discusses aspects of the DOE quality assurance systems that can significantly affect the overall ITER acquisition process and hence many details that feed into the regulatory approval process. These details should be considered in the baseline requirements development task, as described in Section 2.1.

The specific intent of this section is not to reproduce all relevant quality assurance requirements from DOE orders, but to highlight some of them to illustrate the importance of this issue to the overall regulatory approval process. The expected level of quality assurance for ITER will be significantly greater than has been the case for other fusion facilities. Therefore, an extension of approaches taken by the fusion community on previous projects would be insufficient. 
Many of DOE's quality assurance requirements, policies, and procedures are little more than a gathering of good management practices under a quality assurance umbrella. These practices were taken from the literature on quality assurance and from industry experience. A disciplined, systems engineering implementation of the project guidance in DOE $\mathbf{4 7 0 0 . 1}$ would fulfill most of the quality assurance requirements. The DOE quality assurance requirements are not separate and unique, but are essential requirements that would be part of any well managed program or project. This point is clear in many of the standard quality assurance texts, especially Juran (1974).

Quality Assurance is an integral part of any large DOE nuclear project. DOE 6430.1A requires that an adequate quality assurance program should identify and control organizational interfaces; independently verify and control the design; implement a document control system; and implement a change control system. DOE $5700.6 \mathrm{C}$ provides specific quality assurance requirements and 10 quality assurance criteria for a successful quality assurance program. The DOE orders cite other important industry standards, such as ASME-NQA-1 and NQA-2 These standards are useful in developing quality assurance programs. Given the international nature of ITER, the JCT must examine the applicability of ISO 9000 Quality standards (Bureau of Business Practices 1992), the European Community quality assurance standard for ITER.

The level of quality required for ITER will be one of the most important design policy decisions that the JCT must make. Quality will determine the magnitude of resources necessary to perform inspections, prototype testing, verification, documentation, configuration management, and review. The JCT should be aware of the negative experience resulting from quality assurance organizations that, once empowered, gather so much momentum that they impede rather than help the project. The JCT should prevent this pitfall for ITER by adopting a graded approach to quality, much like the safety analysis decisions. Use of the graded approach for fusion activities will break new ground.

The following guideline, which is really a paraphrase of the concept underlying reliability centered maintenance, can be useful in the development of a quality assurance program for ITER: "The level of quality assurance should scale with the relative risk posed by failure of the specific item."

An example of a successful application of the graded approach to quality is the QA program of EG\&G Idaho. Their program provides for three quality levels based on the risk posed by failure of the item:

- Undue risks to workers or public health and safety (level A)

- Degradation of performance or reliability of the item (level B)

- Insignificant risks (level C).

The levels do not alter the basic requirements that must be met. Rather, they provide degrees of latitude in the amount of documentation, formalism, level of record keeping, and traceability required. 
Two key aspects of QA need to be addressed for ITER: design verification and documentation. DOE 5700.6C requires that designs be verified before the output of the design is relied upon to perform its function. Acceptable methods of design verification include design reviews, alternative calculations, and qualification testing. Whenever computer codes are used to perform calculations, the codes themselves must be verified and their results validated (see Section 4.4). Requirements for qualification testing of components are presented in Section 4.5. Because of ITER's first-of-a-kind nature, much of the design will be new and may not be verifiable to the extent required except by testing the actual unit itself. Consequently, some of the pre-operational testing in ITER will be dedicated to verifying design, and continued operation will formally depend upon demonstration that design requirements, calculations, and assumptions are correct.

Another responsibility of the QA function is illustrated by the requirement stated in DOE 6430.1A: "To the extent practicable, and particularly in the case of innovative design, the design should be independently reviewed by competent consultants in construction or manufacturing techniques to confirm the practicability of construction or manufacture." This requirement not only underscores the importance of the DOE requirement for independent review of design activities but also the constructibility as a design criterion.

Documentation is a major consideration for ITER because personnel are working on the project all over the world and documentation is a key medium for intercommunication among them. DOE orders call for the development and implementation of processes to control the preparation, review, approval, issuance, revision, and retention of controlled documents. Controlled documents include but are not limited to

- Drawings

- Data files

- Calculations

- Specifications

- Computer codes

- Purchase orders and related documents

- Vendor supplied documents

- Safety analyses and procedures.

Controlled documents must be retained for the time specified in DOE 1324.2A. Some retention times extend to the life of the project plus 5 years. All documents must be traceable to meet audit requirements.

The importance of document control and records management in a large complex, project cannot be overstressed. It is important to maintain a system (e.g., database) that enables safety 
and design organizations to have access to the current design and also to the safety analysis assumptions (e.g., numbers) that may place constraints on the design. The consequences of a designer or safety analyst using incomplete, outdated, or erroneous data could impact the success of the project. The goal of a document control and records management organization is to provide access to pertinent project information in a timely manner, to ensure that the information is current, and to document the required reviews and approvals. In practice, these organizations tend to become bureaucratic and decrease productivity. The tendency could be made worse for ITER because of the distances between participants. Clearly, the need for documentation control and records management is a high priority for ITER. Therefore, significant attention should be given to the overall quality assurance process developed for ITER and to the document control and records management aspects.

The following guidelines should be considered:

- Keep the responsibility and authority at the lowest possible level in the organization to convince personnel that quality assurance is an integral part of their job and not solely the job of the QA organization

- Limit the number of reviewers on a document to those who really need to review it and whose review will add value

- Structure a simple and transparent document control and records management system so that it does not constitute an obstacle to the work and does not limit or inhibit the communication of results

- Use electronic media as much as possible to increase the speed of communication and to reduce paper volume.

\subsection{Safety Class Items}

Safety class items (SCIs) are a nuclear safety-related issue that requires early attention of the JCT and the entire EDA activity. SCIs have been defined by DOE for nuclear facilities, but the interpretations and applications that have been made are not sufficient to answer all needs of the fusion community. This section presents an overview of the DOE material on the subject, a summary of some work that has been done within the fusion community, and suggestions for future actions by the JCT, the ITER EDA activity, and the fusion community in general.

Safety class (or Class A) items as defined by DOE 6430.1B and 5480.EQ are systems, components, and structures, including portions of process systems, whose failure could adversely 
affect the safety and health of the public, facility personnel, and site workers, and cause unacceptable impact to the environment. ${ }^{c}$ Specifically, they include items

- Whose failures would produce exposure consequences (including radiological and chemical) that exceed an effective dose equivalent of $5 \mathrm{mSv}(0.5 \mathrm{rem})$ at the site boundary or nearest point of public access or to a worker outside the facility

- $\quad$ Required to maintain the operating parameters of ITER within safety limits

- Required to remain functional during and following design basis accidents and external events

- Required to monitor releases during an accident

- Required to maintain the facility in a safe shutdown condition

- $\quad$ Required to provide emergency offsite and onsite communication

- That control the safety class items described above.

The ultimate identification of safety class items will be derived from the ITER safety analysis; however, having these functional descriptions from the outset can materially contribute to the overall design effort for ITER.

Nonsafety class (or Class B) items are those items whose failure would not adversely affect the environment or the safety and health of the public. There is no intermediate class of items between Class A and B. DOE 6430.1A explains that the graded approach can be used to define safety class items by

- Identifying those design basis accident (DBA) events that have the potential for radioactive or chemical releases that threaten the public, the environment, or the worker

- Determining the equipment necessary to prevent or mitigate the effects of the accident and stating its safety function

- Developing the environmental envelope that the equipment must be able to survive based on the DBA events.

For nonreactor nuclear facilities like ITER, DOE 6430.1A requires consideration of the American Society of Mechanical Engineers (ASME) code requirements in the design and

c. DOE 6430.1A, the current version of the General Design Criteria Order, states that safety class items are required only to protect the public but does not address the co-located workers. However, the draft $6430.1 \mathrm{~B}$ and the equipment qualification order, 5480.EQ (draft) both mention the need to protect the worker to the same degree as the public. These criteria are still in draft stage, are the subject of much discussion, and may change. 
fabrication of safety class components. The ASME Boiler and Pressure Vessel Code, Section III, Nuclear Plant Components (ASME 1989) provides requirements for the design of pressure retaining components and has been adopted for power plants. Topics covered by the code include material traceability and testing; minimum strength requirements and allowable stresses; component fabrication, installation, examination, and testing; overpressure protection; and documentation and quality assurance requirements. Applicable components are designated as Class 1,2 , or 3 depending on their intended function and importance. DOE states that safety class items shall be designed to a minimum of Class 2 rules. Thus, as currently written in the order, fusion safety components would not have to be designed to Class 1 rules, which are very restrictive. The ASME Boiler and Pressure Vessel Code was adopted by DOE for fission reactors and some other nuclear applications. We are not aware of any specific application decisions for fusion facilities like ITER (e.g., high neutron fluence). Accordingly this is an issue that will have to be addressed. DOE $6430.1 B$ covers similar applicability questions and states that safety class systems can be designed to other comparable safety-related codes and standards that are appropriate for the system being designed. The order also states that for nonsafety class items the design shall be subject to conventional industrial design standards, codes, and quality standards. However, the EDA activity will have to clarify what structural design criteria and standards are appropriate for fusion materials irradiated to high neutron fluences.

A preliminary assessment of safety class items was performed (Lyon 1990) as part of the ITER Conceptual Design Activities (CDA). In most cases, a system was required to be safety grade because it provided primary confinement for radioactive material or was required to keep ITER in a safe mode during shutdown. His analysis indicated the following safety class items as defined by DOE 6430.1A:

System
Vacuum vessel system
Vacuum pumping system
First wall cooling system
Divertor cooling system
Breeder cooling system
Tritium fuel system

Isotope separation system

Plasma diagnostic attachments

Reason
Primary radioactivity confinement
Primary radioactivity confinement
Safe shutdown cooling
Safe shutdown cooling
Safe shutdown cooling
Primary radioactivity confinement
Primary radioactivity confinement

Primary radioactivity confinement where these systems form a part of torus boundary

The magnets and cryogenic system were not classified in his assessment. However, if analysis of the design of these systems indicates that their failure could result in failure of a safety class system, they would also be designated as safety class. Plasma control systems, such as a fast 
shutdown system that might be required for ITER, were not mentioned but would probably be safety class items. In addition, some of these systems might contain some components that are only Class 2 or none at all if detailed dose calculations based on actual designs indicate that their failure did not result in significant offsite release of radiation.

Remote maintenance systems have not received much attention in this regard. They are required to prevent significant worker exposure for activities within the ITER cryostat. If they failed and manual maintenance were required, a significant increase in worker exposure could result. Thus, remote maintenance systems might be designated as SCIs to protect workers.

Lyon's assessment was based on the ITER CDA design. It is not clear that the first wall/blanket and divertor cooling systems would have to be safety class for the EDA design. ITER might be designed such that failure of these systems would not cause radiation exposures in excess of DOE limits. However, this classification does not consider the protection of workers, which could also influence the number of systems that are safety class. Lyon's work provides a significant base for future fusion development.

Identifying SCIs should be a specific task objective in the EDA, in the safety analysis task, and in the baseline requirements development planning, discussed in Section 2.1. The first two activities would produce the definitive list of SCIs for ITER, as well as implement many of the requirements that derive from an item being an $\mathrm{SCI}$. The third activity, baseline development, would identify the schedules and interfaces associated with the management of the $\mathrm{SCI}$ issue. An integral part of these activities would be the identification of the fusion-relevant requirements in existing directives and the timely negotiation of waivers, exclusions, and exemptions from requirements that are irrelevant to ITER.

DOE 5480.EQ also details the testing requirements needed to qualify SCIs for their use and to verify that adequate margins exist in the design. Testing requires that the key environmental conditions (such as temperature, pressure, humidity, chemical effects, radiation, electromagnetic effects, aging, and seismic effects) be known and that synergistic effects be considered. All documentation should follow DOE $5700.6 \mathrm{C}$ on quality assurance (see Section 4.2). In addition, DOE 6430.1A indicates that all systems for which regulatory credit is taken to meet the accident release criteria (discussed in Section 3) must be tested in-place for "pressure, filtration or removal efficiency, alarm capability, leak resistance, and the like." In addition, SCIs must be designed to be tested regularly. Recommendations regarding acceptable test programs are discussed in Section 4.5.

The entire issue of SCls and equipment qualification raises some interesting questions relative to fusion and ITER. In fission reactors, many of the safety systems tend to be separate, easily identified standby systems or components that must be used during a transient, such as the emergency core cooling system, the residual heat removal system, and containment spray system. In fusion, with increased emphasis on safety in design, the safety of the system is a more integral part of the machine. Existing components, in addition to their primary design function, may have more than one safety function (e.g., the vacuum vessel has both radioactivity confinement and decay heat removal safety functions). Thus, there may be fewer discreet, external, single-function $\mathrm{SCIs}$ in a fusion machine. This small number suggests that the conventional fission safety classification of systems may not be entirely appropriate to fusion. An alternative classification 
system that capitalizes on the technical differences between fission and fusion different must be considered for ITER for a favorable regulatory approval process without impacting the overall cost.

\subsection{Verification and Validation of Computer Codes}

The issue of verification and validation (V\&V) of computer codes for ITER is somewhat analogous to the issue of quality assurance, Section 4.2. The issue may not have received enough attention in fusion applications to meet current DOE requirements. For that reason, this section describes DOE V\&V requirements that the JCT should consider in the framework for ITER regulatory approval. This section includes some experiences from DOE applications and guidelines to clarify the options for JCT understanding.

\subsubsection{Requirements}

Computer codes are being used to perform the design and safety analyses for ITER. DOE requires that such computer codes be verified and validated under DOE 5700.6C and DOE 1330.1D to ensure that the results that are obtained are meaningful and that the program has assurance that the design and safety basis are sound. In general, V\&V should be performed before the PSAR and Title II design for the facility begin.

Many of the standards and requirements used to verify and validate nuclear safety-related computer codes were developed by the NRC for the licensing of commercial nuclear power plants. The requirements are embodied in ASME NQA-1 and ASME NQA-2 standards. In addition, several American National Standards Institute (ANSI)/Institute of Electrical and Electronic Engineers (IEEE) standards (ANSI/IEEE STD 730, 828, 829, 830, 983, and 1012) are used as guides. These standards state that codes used in the design or safety analysis of a system must be verified, validated, and controlled to provide assurance for documentation of changes or modification.

Verification is defined as the process of determining whether or not the software is coded correctly and conforms to the specified software requirements. Strictly speaking, full verification would require a line-by-line check of the entire computer code to ensure correctness. However, other less stringent methods are considered applicable, such as developing a series of calculational cases or input decks that test much of the logic in the code to ensure that the code performs as stated in the theory or user's manual. The level of detail and rigor is defined in the V\&V plan and is based on the intended application of the code, as discussed later in this section. As a general rule, all design and safety analyses should be verified to some extent because it is good engineering practice.

Validation is defined as the process of evaluating software to ensure compliance with software requirements and physical applicability to the process being modeled. Validation is generally more involved than verification. Validation of a code would consist of comparing it with known analytic solutions for problems similar, yet perhaps simpler, than the problem at hand. It would also include benchmarking the code against relevant experimental data, thus ensuring that the analysis reasonably captures the correct physics and chemistry. It could also include comparison against an already validated computer code. A code would be considered validated if 
it met the predetermined acceptance criteria. An example of an acceptance criterion is that the code results agreed with the data within a predetermined factor or produced results that agreed with another validated code.

The number and type of benchmarking problems needed to validate a code is a strong function of the complexity of the phenomena being modeled, the code's range of applicability, and the data that are or could be available. For a complicated computer code, verification could require that all individual models and submodels in the code be verified and validated against separate-effects data and that integral validation of the code also he performed. All of these issues are a function of the specific technical area and need to $b$ : considered in the respective $V \& V$ plans. Full V\&V can cost as much as developing the original code.

For a code to be considered validated at a given quality level (see Section 4.2), the key data with which it is compared should be of the same quality level. Thus, V\&V requirements for codes can impact the type of database and testing that are necessary. Database development and testing are discussed in Section 4.5.

EG\&G Idaho has developed a graded approach for the software quality control level required for safety and design analyses of DOE facilities. The three quality levels $(A, B$, and $C)$ defined in Section 4.2 on quality assurance are applied to software. None of the formal V\&V requirements are imposed on quality level $C$ work. For quality level $A$ and $B$ computer codes, ANSI/IEEE standards on V\&V are used as guidelines. For a code to be quality level $A$, strict adherence to the standards is required. For a code to be quality level $B$, there is more latitude, and engineering judgment plays a role in determining the adequacy of the V\&V. Both level $A$ and $B$ codes require that a software quality assurance plan be written. The plan documents the functional requirements for each piece of software, the acceptance criteria to be used in the V\&V process, the approach to be taken to verification and validation, and the software configuration control strategy that would be used. In addition to this plan, user's and theory manuals are written and the results of V\&V are documented. Finally, documentation is provided to manage configuration control of the software itself. This process is relatively time consuming and expensive. Quality levels $A$ and $B$ require that this documentation be prepared and that configuration control be established; however, the level of detail and rigor in the verification and validation differs.

\subsubsection{Experience from DOE Applications}

We have examined some recent DOE programs to determine the quality level appropriate for computer codes used in ITER. The results indicate that the degree of V\&V varies significantly because of a difference in interpretation relative to implementation of the standards. The degree appears to be strongly correlated to the size of the budget in the program. In the New Production Reactor program, extensive V\&V was planned for the Modular HighTemperature Gas Reactor codes before the program ended. The reactor would have been a Class $\mathrm{A}$ reactor facility and categorized as a Category 1 hazard. The approach used was very similar to that used in the commercial nuclear reactor industry and would have met the quality level $A$ requirements discussed earlier. The V\&V would have required substantial resources to implement. In fact, the program spcint 2 years developing the software requirements document 
for their large-system behavior code. The code was never actually developed before the program ended.

By contrast, the effort to restart the Savannah River production reactors and the safety analyses for the Advanced Test Reactor (ATR) at the INEL involved less V\&V of safety codes because of serious practical limitations, as discussed below, even though both reactors are Class $A$. Category 1 hazard facilities. First, many of the codes used to analyze the safety of the plants were deemed to qualify as quality level $C$. Even if the codes were fully verified to quality level $A$ standards, many of the codes contain empirical correlations (e.g., heat transfer correlations, materials correlations) based on data generated without traceable quality control (i.e., pedigree is a term used to express the careful documentation of sources and data). Thus, in terms of quality level, the code is only as good as the data and correlations it contains. In many cases, the best state-of-the-art computer code can only be qualified as quality level $\mathrm{C}$ because of these concerns. Therefore, the approach used for the Savannah River project ${ }^{d}$ consisted of identifying the key computer codes used to set operating and safety limits in the reactor and bringing them under configuration control. Then, the correlations in the code were reviewed for applicability, and the codes were verified and validated using the procedures required for quality level B, even though the cucie iiself ivould be inherently quality level C. A series of specific bounding experiments were iderifified by technical experts and performed to obtain quality level B type data for the validation effort. Verification would be performed on the codes, and all work would be reviewed and documented for traceability. This approach was taken largely for practical reasons, given the program budget; however, it was approved by both quality auditors and safety review boards. A similar approach, though somewhat more limited in scope, was used for the ATR safety analysis.

These case studies indicate that program constraints influenced the methods pursued for V\&V. Given limited budgets, the programs decided to do what made sense technically and still complied with the spirit of the DOE orders. Full V\&V to quality level $A$ standards could not have been achieved because of inherent limitations in the computer codes and the large amount of resources needed to do such a project. Moreover, the value of qualifying a safety computer code to the quality level $\mathrm{A}$ requirements was questioned, given the concern about the lower quality of data used in some of the correlations. These results are fairly promising for ITER. Even if ITER is declared a Category 1 facility, there is precedence in the DOE system to adopt a V\&V program that makes technical sense and can be accomplished within reasonable cost. If ITER is determined to be a Category 2 facility then an approach similar to that described above would seem to be technically sound.

\subsubsection{Guidelines for the JCT}

Based on reviews of practices in a few DOE programs, the following guidelines are offered for consideration for ITER:

- The ITER JCT must determine the overall V\&V guidelines that will be used for design and safety analyses. Detailed, lower level requirements cannot be developed universally for the project because they are a strong function of the technical area, the safety

d. The approach used by Savannah River to V\&V their safety codes was developed by EG\&G Idaho. 
criteria developed by the JCT, and the relative contribution of each area to the total risk of ITER. Instead, the JCT should develop a policy and philosophy that relate the amount of $\mathrm{V} \& \mathrm{~V}$ required, and hence the resource allocation, to the relative risk of each area, which is the graded approach concept. In general, more resources and more technical attention will be required in areas where safety margins in the design are smaller and the impact on overall risk is greater.

- The respective Home Teams need to develop V\&V plans for each of their safety and design codes. The plans need to set specific functional requirements and acceptance criteria for the codes in light of the overall ITER philosophy. Because of the general lack of data in many areas, a group of technical experts who understand the technology, the computer code, and the associated database should agree on the approach. The detailed requirements and acceptance criteria for validation are expected to vary from technical area to technical area depending on the risk consequence aspects of the specific item. For example, a code could be considered verified and validated if it matched the data within $25 \%$, whereas in other cases a factor of five may be acceptable if the impact of the result on the overall design margin or safety risk is small. The technical experts must assess the current phenomenological understanding as embodied in the codes and the available database, and identify any new data that must be generated to help validate the model for ITER. The codes must be put into some form of configuration control. The experts must also develop a set of relevant benchmark experiments and test probi : ' is to be used in the validation, remembering that the quality of the validation is : : ly as good as the quality of the underlying database. These benchmark experiments should bound the range of conditions expected in ITER as much as possible. Finally, the experts must focus only on validation for ITER. ITER does not have the funds to validate a code under non-ITER relevant conditions.

- Finally, for much of the work done in the past, codes were validated by comparing the results with a series of bounding data obtained from well-controlled experimental programs under an appropriate quality assurance program. Thus, the validation defined an acceptable envelope in which the code results were considered reasonable. For ITER, much of its intended application is an extrapolation from a smaller database of existing fusion experimental devices. It may not be possible to obtain bounding data for validation because fusion is an emerging technology. as opposed to an established technology like fission. Many of the early fission reactors played a similar role in terms of providing the technical data needed to develop maturity in the overall fission reactor technology. However, there were no universally required or accepted V\&V requirements in the early days of fission. Even today, for safety analyses of existing DOE reactors, the actual facilities have been tested to obtain required validation information. The burden of proof will be more difficult for a machine like ITER that has yet to be built. These concerns need to be examined b: the technical experts in each area to determine the degree of extrapolation and the associated risk. Preoperational testing in ITER will probably be necessary. In other cases, such as plasma physics issues concerning ignition and control, the extrapolation risk may be present until ITER is actually operating. 
This approach should be studied and understood by the JCT and the developers of the baseline requirements to ensure that all specific requirements are adequately defined and that all interfaces are reflected in the long-range planning and resource identification tasks.

\subsection{Experimental Databases}

Experimental databases are not a unique issue to ITER, but some aspects warrant early consideration by the JCT because of their impact on overall scheduling, allocation of resources, and in some cases the need for planning because of the long lead time that results from special data and test needs. Both the safety analysis and design activities may impose requirements on experimental data needed for ITER.

Experimental databases will be needed to support the design, safety analysis, and the regulatory approval process for ITER. In general, three types of databases are envisioned:

- Tests to understand basic phenomena related to ITER safety [e.g., activation product mobilization and transport, off-normal plasma behavior, loss-of-coolant-accident (LOCA) response, and tritium release] for use in safety computer codes to support the safety analysis (DOE 5480.23)

- Tests to qualify safety class items (e.g., fast plasma shutdown systems, radioactivity confinement, detritiation and radioactivity filtration systems, and vacuum vessel cooling system) under DOE 5480.EQ

- Tests to verify the design of components and systems for ITER (will show that the system or component works) under DOE 6430.1B and DOE 5700.6C.

The following sections describe testing requirements from the DOE orders, highlight the relevant technical issues relating to adequacy of a test program and resulting database, and discuss some selected data quality issues.

\subsubsection{Requirements}

DOE 5480.EQ and DOE 5700.6C state the following requirements for developing an acceptable testing program:

- ITER must have access to facilities, qualified personnel, procedures, and an approved QA program

- IEEE STD 600 should be used for guidance on implementing a test program

- All test data and reports must be maintained in an auditable file

- An auditable link must connect the test unit and the installed. equipment

- Tests must be conducted under normal operating conditions and at the extremes of all mechanical and electrical performance levels 
- Where aging is a concern, the equipment should be aged and then teated under both normal operating and design basis accident conditions.

The following teating methods are acceptable to comply with DOE 5480.EO:

- Teating an identical item under identical or similar conditions with analysis to show qualification

- Teating a similar item with supporting analysis io show qualification

- Using operating experience with identical or similar equipment under similar conditions with analysis to show qualification

- Using analysis and partial type test data that supports the assumptions and conclusions to show qualification

- Aging analysis.

DOE 5480.EO provides stringent requirements for the documentation needed for a safety test program. Testing needs to be conducted following an approved test plan (which usually requires independent peer review) and approved operating procedures. There must be an adequate quality assurance program to ensure the quality of the data collected. Data must be retained in auditable files. These requirements will add both time and money to the cost of R\&D testing programs. Furthermore, the additional formalism in the documentation (e.g., test plans and procedures) will result in reduced flexibility in terms of the program's ability to accommodate changes in scope in the test program when new technical information or questions arise. As a result, a less formal test capability should be retained to resolve unforeseen technical questions. This alternative test capability can provide scoping data quickly to evaluate a technical issue, yet it will not impact the formal test program. Any changes in direction suggested by the scoping data can be accommodated cost effectively.

\subsubsection{Adequacy Concerns}

Despite the degree of formalism required by DOE 5480.EQ, some flexibility exists in the methods of testing to be used and the proper mix of testing and data needed to produce a credible safety or design database. However, much of the testing for ITER (as for other nuclear facilities) can never exactly simulate the conditions expected. Therefore, questions will always arise about the adequacy and completeness of the testing program. Moreover, the approach that is used to verify and validate the computer codes will impact the amount of data and type of testing that are needed. Sound engineering judgment and technical logic will be needed to determine the optimum mix of testing.

Databases developed in the fission industry can be used as a starting point for the technical issues that must be considered in selecting the testing and judging the adequacy of the database that is needed. Historically in the fission community, the type of testing has been driven by three effects: scale, complexity of phenomena to be studied, and environmental effects. 
The issue of scale is one of prototypicality. Small-scale laboratory tests are relatively inexpensive, but may not be prototypic of the engineering system or structure. Teating can be performed using scaled facilities or components. However, scaling is sometimes a controversial technical issue for two reasons: How adequate is the scaling law and how much extrapolation must be used to describe the actual behavior of the system? Prototypic testing is more expensive, but can provide direct information on the performance of a system or structure. In most fission projects, all three types of teating have been used. Clearly, for moderate sized components or systems, prototype testing is cost effective and produces the least uncertainty. When the actual component or system is too large to test, either scaled testing or in situ testing can be used. Careful planning must be used in developing scaled test facilities.

The complexity of the phenomena to be studied determines the mix of separate-effects testing and integral testing required. In cases where the phenomena to be studied are fairly simple, separate-effects tests are probably adequate. However, if important competing materials interactions, physical phenomena, or chemical reactions determine the ultimate behavior of a system or structure under specified conditions, integral testing is also necessary. The complexity of the analysis tool or computer code used to understand the phenomena or system is also important here. For example, if the computer code is a set of submodels that must interact in a complex way, each submodel must be tested as well as the entire code. Such issues should be addressed in the computer code V\&V plan, which would then impact the R\&D testing.

Radiation is an environmental effect that should be considered in developing the test program for nuclear components. If irradiation effects are not important, out-of-pile experiments are probably adequate. If irradiation effects are important, irradiated material, in-pile experiments, or both are also necessary. Furthermore, the lack of a $14 \mathrm{MeV}$ neutron source for studying material irradiation behavior is a key weakness, the impact of which will need to be addressed in any fusion material testing program and database. For fusion, there is also a concern about thermal cycling and the electromagnetic environment and their potential impacts on the behavior and reliability of equipment.

Finally, DOE 5480.EQ states that testing programs should consider synergistic effects. Thus, the coupled effects of radiation and magnetic fields should be considered for some components.

Because of its first-of-a-kind nature and mission, the databases for ITER may not have the same scope and depth as comparable fission databases. In addition, some testing issues, such as synergistic effects, radiation damage (i.e., lack of a $14 \mathrm{MeV}$ neutron source), and scale probably cannot be addressed in existing facilities and could only be addressed by ITER itself. Thus, some pre-operational testing with ITER or ITER components must be performed before receiving approval for D-T operation. For example, testing the magnets in situ may be required to qualify them for operation. However, even with some operational experience in ITER, the lack of a robust database at full neutron fluence will limit the amount of safety credit that can be taken for some irradiated components, such as the first wall, blanket, and divertor.

\subsubsection{Quality Concerns}

Two issues related to the quality of the database that is developed need mention here. First, the quality program set up for ITER would determine the amount of formalism needed in 
performing analyses and conducting experiments. In most cases, data quality from a quality assurance standpoint refers to using approved procedures, maintaining adequate records, and being able to trace the work that is performed.

Second, the accuracy of the data depends on whether or not the data that have been gathered are correct or valid for the intended purpose. A possible approach to addreasing this issue is the EG\&G Idaho Data Review Committee (DRC) established to evaluate the data. The DRC members have certain expertise, usually a QA person, an instrumentation or measurement person, a person who understands the tests or experiments, and perhaps a user of the data. They act as a peer committee to determine if the data make sense and can be validated. The concept of peer review may be regarded as the best way to evaluate data from the R\&D work because it is generally state of the art.

\subsection{Level of Technical Understanding}

Technical understanding of the results of the R\&D activities is as important as all previous issues. Technical understanding in not an issue in the same sense as quality assurance, for example, which demands meeting prescriptive requirements. Rather, technical understanding is an issue in the sense of a mandatory capability of ITER personnel. One reason for this importance results from the increasing role of peer review in large nuclear projects. In general, peer reviewers will be much more interested in the basic science, and how well presenters understand the gathered data than in whether all proper procedures have been followed. The greater fundamental understanding that is gained, the more credible any extrapolations required for qualification will be viewed. The required level of fundamental understanding is a function of the technical area. In general, empirical data are viewed more skeptically by reviewers than data that can be explained with phenomenological models. Clearly, the issue of balance is important here.

Consequently, the JCT should ensure that the requirement for a fundamental technical understanding is formally identified in the baseline requirements and in all subsequent project management documentation. Identifying it as such will allow adequate planning and guaranteed resources. These actions will ensure that the Parties use a system that communicates the fundamental technical understanding. This communication is necessary to convince a peers that the risk of designing, building, and operating ITER is identified, quantified, and acceptable based on the Parties' understanding of the fundamental behavior of the total facility system in its intended operational program.

\subsection{Tritium Accountability}

The DOE requirements for tritium accountability should be mentioned here as a nuclear safety-related technical issue. These requirements must be evaluated in the baseline requirements phase of ITER to ensure that they do not hinder the performance any essential elements of the ITER program or to negotiate the exclusions or waivers that may be required.

Tritium is a nuclear material of strategic importance and thus is subject to the control and accountability requirements stated in DOE 5633.3A. The DOE order classifies tritium as "other nuclear material," and the reportable quantity is $0.01 \mathrm{~g}(100 \mathrm{Ci})$. The order implements a graded 
material control and accountability program. The order describes classification procedures to categorize nuclear materials safeguards (I, II, III, and IV), depending on the type of nuclear material and its attractiveness (i.e., a measure of the ease with which the material can be used to make a weapon). Tritium is classified as nonspecial nuclear material and is given a Category IV rating. The order provides requirements for materials accountability (e.g., accounting systems, inventories, measurements and measurement control, material transfers), materials control (e.g., access crntrol), materials surveillance and containment, and detection and assessment.

For ITER, dealing with the 100-Ci reportable requirement would be very difficult given the large quantity of tritium that will be in the facility. Moreover, DOE 5633.3A states that for new facilities the planning, design, construction, and operation should incorporate the latest material control and accountability technologies, systems, and approaches. Verbatim compliance with DOE 5633.3A could have a serious negative impact on ITER fuel cycle design. Thus, this issue needs early JCT attention.

\subsection{Emergency Planning}

The ITER Technical Advisory Committee, in its second meeting, set a goal of requiring no offsite emergency planning (i.e., no public evacuation) for ITER. Implementation of that goal by the JCT/TTER management will have a major effect on the ITER project for both siting and design. This section briefly describes the DOE requirements for and approach to emergency planning. This description illustrates the nature of the issue and some of its ramifications on the regulatory approval process for ITER. As for the other issues in this section, the emergency preparedness requirements must be stressed and project policy defined for completeness in the baseline requirements development, and for early negotiation of waivers and exclusions based on fusion relevant technology.

DOE 5500.1B, 5500.2B and 5500.3A present the DOE emergency planning and management system, including classification of emergency events, notification and reporting requirements, and planning and preparedness requirements. The purpose of these orders is to develop requirements for planning, preparedness, and readiness activities in the event of an emergency.

DOE developed three categories of emergencies (operational, energy, and continuity of government) and classes within each category that are commensurate with the potential hazards of the emergency conditions. An operational emergency is defined as a significant accident, incident, event, or natural phenomenon that could seriously degrade safety or security at the DOE facility. Energy and continuity of government emergencies require responding to actual or potential disruptions of the nation's energy supplies and threats to security, respectively. For reactor and nonreactor nuclear facilities, operational emergencies apply.

The three classes of operational emergencies are alert, site area emergency, and general emergency. An alert for a facility like ITER would be declared for an event in which an actual or potential degradation in the level of safety of the facility is in progress or has occurred. Any release of radioactive material is expected to be a small fraction of the protective action guidelines (PAGs), as discussed in Section 3. A site area emergency would be declared for an event in which actual or likely major failures of facility functions needed for protection of the workers or public is in progress or has occurred. Any release of radioactive material is expected 
to exceed the PAGs onsite but not offsite. Thus, protective action of onsite workers is required. A general emergency would be declared if an event in which actual or imminent catastrophic reduction of facility safety systems with potential for loss of hazardous material containment or confinement is in progress or has occurred. Releases in these events are expected to exceed the PAGs offsite. Protective actions for offsite general public is required.

All DOE facilities need to establish and maintain emergency management programs consisting of plans and procedures to respond to operational emergencies. The program must be commensurate with the assessment of potential hazards at the facility. Three hazard levels are identified: high, moderate, and low.

The emergency planning hazard assessment is the technical basis for the emergency management program. The assessment must consider a broad range of emergency events that could affect the facility that result from

- Operation

- Accidents

- Earthquakes and other natural phenomena

- Hostile acts

- $\quad$ Terrorism

- Sabotage

- Malevolent acts.

Design basis accidents and their associated assumptions can be used as a starting point, but the order requires that a broad spectrum of events from minor occurrences to beyond design basis events need to be considered. Vulnerability and target analyses, which are usually classified, should also be considered. Thus, this assessment differs from that required as part of the safety analysis specified in DOE 5480.23 and DOE STD 1027.

For each potential operational emergency, the assessment must address

- The initiating event

- Accident mechanisms

- Equipment or system failures

- Event indications

- Contributing events 
- Source terms

- Material release characteristics

- Topography

- Environmental transport, diffusion, and exposure considerations.

The assessment must also determine the size of the emergency planning zone (EPZ). The EPZ is the area surrounding the facility for which special planning and preparedness efforts are required to ensure that prompt and effective protective actions can be taken to minimize the risk to workers, the general public, and the environment.

In the emergency planning orders, there is an implicit correspondence between hazard categorization (high, moderate, or low), operational emergency class, and dose thresholds. Recall that the safety analysis hazard classification also categorized facilities in a similar manner according to their risk consequence:

Category 1-potential for significant offsite consequences

Category 2-potential for significant onsite consequences

Category 3-potential for significant localized consequences.

However, the dose threshold was not defined for a Category 1 facility. With these definitions, the following correspondence can be made:

Table 5. Hazard assessments, emergency classes, and PAG limits.

\begin{tabular}{|c|c|c|c|}
\hline \multicolumn{2}{|c|}{ Hazard Assessments } & \multirow{2}{*}{$\begin{array}{c}\text { Maximum } \\
\text { Operational } \\
\text { Emergency Class }\end{array}$} & \multirow[b]{2}{*}{$\begin{array}{l}\text { PAG } \\
\text { Limit } \\
\end{array}$} \\
\hline $\begin{array}{l}\text { Safety } \\
\text { Analysis }\end{array}$ & $\begin{array}{l}\text { Emergency } \\
\text { Planning }\end{array}$ & & \\
\hline 1 & high & General & $10 \mathrm{mSv}$ (1 rem) offsite \\
\hline 2 & moderate & Site Area & $10 \mathrm{mSv}(1 \mathrm{rem})$ onsite \\
\hline 3 & low & Alert & Fractions of $10 \mathrm{mSv}$ (1 rem) \\
\hline
\end{tabular}

ITER could more easily obtain regulatory approval if, at that time, it could describe an established interpretation of the correspondence between the hazard categorization for emergency planning and the hazard categorization for safety analysis. This correspondence is not adequately addressed in DOE guidance documents and could delay receiving regulatory approval if the reviewers do not have a common technical understanding of the basic underlying issues. Such an approach might preclude the need for negotiated waivers, exemptions, and exclusions.

The ITER Technical Advisory Committee has established a goal that ITER be designed such that offsite emergency planning is not required. It is not obvious how this goal could be 
realistically accomplished, given the wide spectrum of events that must be considered in the emergency planning hazard assessment (e.g., sabotage, terrorism, or malevolent acts). In many of these events, credit might not be allowed for any active safety systems, and perhaps even for passive safety systems, resulting in potentially large releases to the environment. One way to avoid offsite emergency planning, given the uncertainty in interpreting the type of accident sequences that must be considered, would be to site ITER on an isolated DOE reservation where a large emergency planning zone would not encompass any significantly populated area. 


\section{GUIDELINES FOR THE JCT}

This section provides some top level guidance criteria that, based on our study of the requirements for obtaining regulatory approval of ITER, would have the greatest impact on the development of a successful framework for structuring the JCT/ITER approach to obtaining such approval. These criteria are specifically not a compilation of the suggestions or needs identified in the earlier sections of this report. Rather, we have attempted to extract key criteria that would be the most beneficial to top decision makers in the Parties and the JCT. In addition to the specific guidance criteria, this section discusses other relevant subjects that are not guidance criteria.

The guideline criteria are

- Maintain an approach that focuses on needs of fusion and ITER to ensure that the requirements of this technology are foremost in the decision processes and that the history and experience of the fission industry are kept in proper perspective, neither being blindly adopted nor summarily dismissed.

- Recognize ITER's experimental nature in the development of regulatory requirements.

- Focus on hazard reduction and passive or inherent safety design solutions as a means of preventing accidents.

- Implement a graded approach policy in the overall management of the project such that all requirements are proportionate to the associated risk.

- Integrate the use of risk- and cost-benefit analyses into the overall graded approach system to help guide the development of licensing requirements as much as possible.

- Implement a policy of detecting and fixing problems at the source at the earliest time possible.

- In the process to review and adopt ITER requirements, highlight the importance of not stifling innovative approaches in design and safety by the adoption of any requirement.

- Implement a configuration management policy that will result in a mir.imum number of separate documents used to define requirements, thus reducing the potential for contradiction and conflict, and enhancing the probability of always being in compliance.

- Structure the baseline development task to identify the information required for ITER planning in such a way that the Home Teams can both participate in the identification of all relevant requirements for their countries and also monitor changes in their countries' requirements. Charge the Home Teams with keeping the JCT informed of all relevant regulatory developments. Delegate to the home teams the lead responsibility for negotiation of waivers and exclusions of potential host country requirements. 
The information in this report is strongly focused on the requirement of one of the ITER Parties, the U.S. Gathering the experiences of all Parties in similar efforts would be of significant value to the JCT in the development of its regulatory approach framework. However, unless delegated to the Home Teams, such an encompassing task would unduly burden the limited ITER resources. As a minimum, the JCT needs to develop an understanding of the general regulatory requirements of each of the Parties and to identify the specific requirements that are sensible and technologically defensible for ITER.

ITER will be a first-of-a-kind machine, which will pose unique challenges for the fusion community, especially in the regulatory arena. For safety issues, it is important to acknowledge that ITER is an experimental machine. As such, uncertainties will exist and some questions that might be raised in the regulatory review process will not have complete answers (e.g., How does an ignited plasma behave? What are the effects of $14 \mathrm{MeV}$ radiation damage to plasma facing components and structural materials? How will the divertor behave under a given off-normal condition?). It follows then that the regulatory strategy must show that ITER can meet its safety requirements without having to rely on components that are either experimental or cannot be fully qualified in a separate test program (e.g., divertor, first wall, and blanket). A simpler and more demonstrable safety approach is one that relies on more stringent radioactivity confinement barriers, such as the vacuum vessel and cryostat. Such an approach has precedence in U.S. fission irradiation test reactors, where testing of components or structures would be performed under conditions where the behavior was uncertain. In these cases, a robust radioactivity confinement barrier surrounded the test article, and safety calculations showed that there were no credible challenges to the barrier.

Regulators tend to be fairly conservative as a group. In fission technology, they have tended to be more comfortable with evolutionary designs, such as the advanced pressurized water and boiling water reactors, and the corresponding prescriptive requirements than with revolutionary advanced fission reactor designs, such as the gas and liquid metal reactors. Interactions among the advanced fission reactor design community and regulators indicate that new technologies with innovative approaches to safety and design (e.g., lack of containment, mechanistic source terms) have faced significant institutional inertia in gaining acceptance. Regulators must first understand the new technology before they can understand the safety philosophy or approach that is being pursued. This education process takes time, and for ITER it will be even more important because fusion is a significantly different technology from fission. Therefore, the safety and regulatory personnel of ITER must educate the regulators about fusion, ITER, and ITER's approach to safety. This large challenge will be very important to the overall success in obtaining regulatory approval of ITER.

One final observation regarding the current status of the DOE regulatory system warrants discussion. Many in the fusion community have stated that the current DOE regulatory system is changing, that many DOE orders relevant to fusion are either in draft or are being changed, that a fusion-specific order (DOE 5480.FUSION) is being developed to correct many of the system deficiencies, and that the uncertainties in this system are a major obstacle to obtaining regulatory approval. Overall fission reactor experience indicates that the regulatory requirements and DOE (and predecessor) directives have always been in a state of change. We believe that the current situation is not a difference in kind, but one of degree. All nuclear technology planning has dealt with uncertainties and planned for eventualities. In some instances the planning was adequate, in 
others it was not. One negative example is the SPERT IV reactor at the INEL, which stood idle for one year after the physical plant construction activities were complete and before its initial nuclear operation, a victim of changing requirements from the government customer. Projects must be alert for potential changes, but it is unreal to expect to operate in an environment where requirements are fixed and no further changes are allowed. 


\section{REFERENCES}

American Society of Mechanical Engineers

ASME, Boiler and Pressure Vessel Code, Section III, Nuclear Plant Components, 1989 Edition.

ASME NQA-1, Quality Assurance Program Requirements for Nuclear Power Plants, August 1979.

ASME NQA-2, Quality Assurance Requirements for Nuclear Power Plants, 1983.

American National Standards Institute and the Institute of Electrical and Electronic Engineers

ANSI/IEEE STD 600, IEEE Trial-Use Standard Requirements for Organization that Conduct Qualification Testing of Safety Systems Equipment for Use-In Nuclear Power Generating Stations, Draft.

ANSI//EEE STD 730, IEEE Standard for Software Quality Assurance Plans, 1984.

ANSI/IEEE STD 828, IEEE Standard for Software Configuration Management Plans, 1983.

ANSI/IEEE STD 829, IEEE Standard for Software Test Documentation, 1983.

ANSI/IEEE STD 830, IEEE Guide to Software Requirements Specification, 1984.

ANSI/IEEE STD 983, IEEE Standard for Software Quality Assurance Planning, 1986.

ANSI/IEEE STD 1012, IEEE Standard for Software Verification and Validation Plans, 1986.

Brynda, W. J., et al., 1986, Nonreactor Nuclear Facilities: Standards and Criteria Guide, DOE/TIC-11603 Rev 1, BNL-51444 Rev 1, September.

Bureau of Business Practice, 1992, ISO 9000, Handbook of Quality Standards and Compliance, Waterford, CT: Prentice Hall.

EG\&G Idaho, Inc., 1992, "Radiological Controls Manual," Idaho Falls, Idaho, December.

Fetter, S., E. T. Cheng, F. W. Mann, 1990, "Long-term Radioactive Waste From Fusion Reactors: Part II," Fusion Engineering and Design, 13, pp. 239-246.

Juran, J. M., (ed.), 1974, Quality Control Handbook, 3rd Edition, New York: McGraw-Hill.

Kocher, D. C., and A. G. Croft, 1989, A Proposed Classification System for High Level and Other Radioactive Wastes, ORNL/TM-10289, Oak Ridge National Laboratory, Oak Ridge, TN. 
Lyon, R. E., 1990, "Nuclear Grade Classification for ITER, Safety Task 1.5," ITER-IL-SA-4-0-5, SE-T1-03(US)1/90, January.

Reilly, H. J. (EG\&G Idaho, Inc.), 1993, letter to S. Rossi (DOE-OFE), "April 30 Deliverables," Enclosure 2, Review of DOE Orders, HJR-12-93, April 26.

Syracuse Research Corporation, 1991, Taxicological Profile for Beryllium, U.S. Department of Health and Human Services, Draft, October.

U. S. Code of Federal Regulations

Title 10 CFR 61, Licensing Requirements for Land Disposal of Radioactive Waste, U.S. Nuclear Regulatory Commission, 1992.

Title 40 CFR 61, Subpart H, National Emission Standard for Radionuclide Emissions from Department of Energy (DOE) Facilities.

Title 40 CFR 141, National Interim Primary Drinking Water Regulations (Safe Drinking Water Act).

Title 40 CFR 191, Environmental Standards for the Management and Disposal of Spent Nuclear Fuel, High-Level and Transuranic Wastes.

U.S. Department of Energy (DOE)

DOE 1324.2A, Records Disposition, Chapter V, Records Schedules, April 1992.

DOE 1330.1D, Computer Software Management, May 1992.

DOE 4700.1, Project Management System, March 1987.

DOE 5400.5, Radiation Protection of the Public and Environment, February 1990.

DOE 5440.1E, NEPA Compliance Program, November 1992.

DOE 5480.5, Safety of Nuclear Facilities, September 1986.

DOE 5480.11, Radiation Protection for Occupational Workers, December 1988.

DOE 5480.19, Conduct of Operations, May 1992.

DOE 5480.21, Unreviewed Safety Questions, December 1991.

DOE 5480.22, Technical Safety Requirements, September 1992.

DOE 5480.23, Nuclear Safety Analysis Reports, April 1992. 
DOE 5480.28, Natural Phenomena Hazards Mitigation, January 1993.

DOE 5480.31, Startup and Restart of Nuclear Facilities, September 1993.

DOE 5480.EQ, Equipment Qualification for Reactor and Nonreactor Facilities, Draft, May 1992.

DOE 5480.FUSION, Safety of Fusion Test Facilities, Proposed Draft, 1993.

DOE 5481.1B, Safety Analysis and Review System, May 1987.

DOE 5500.1B, Emergency Management System, February 1992.

DOE 5500.2B, Emergency Categories, Classes, and Notification and Reporting Requirements, February 1992.

DOE 5500.3A, Planning and Preparedness for Operational Emergencies, February 1992.

DOE 5633.3A, Control and Accountability of Nuclear Materials, February 1993.

DOE 5700.6C, Quality Assurance, August 1991.

DOE 5820.2A, Radioactive Waste Management, Chapter 5, Decommissioning of

Radioactively Contaminated Facilities, September 1988.

DOE 6430.1A, General Design Criteria, March 1989.

DOE 6430.1B, General Design Criteria, Draft in progress.

DOE STD 1027-92, Hazard Categorization and Accident Analysis Techniques for Compliance with DOE 5480.23, Nuclear Safety Analysis Reports, December 1992.

DOE-DP STD 3009, Preparation Guide for U.S. Department of Energy Nonreactor Nuclear Facility Safety Analysis Reports, Draft 1993.

DOE Rules, Procedural Rules for DOE Nuclear Facilities, 10 CFR 820, August 1993; Nuclear Safety Management; Contractor and Subcontractor Activities, Draft 10 CFR 830, December 1991; Radiation Protection for Occupational Workers, Draft 10 CFR 835, December 1991.

U.S. Environmental Protection Agency

U.S. EPA, 1975, Manual of Protective Action Guides and Protection Actions for Nuclear Incidents, EPA-520/1-75-00, September.

NEPA, 1969, National Environmental Policy Act of 1969. 

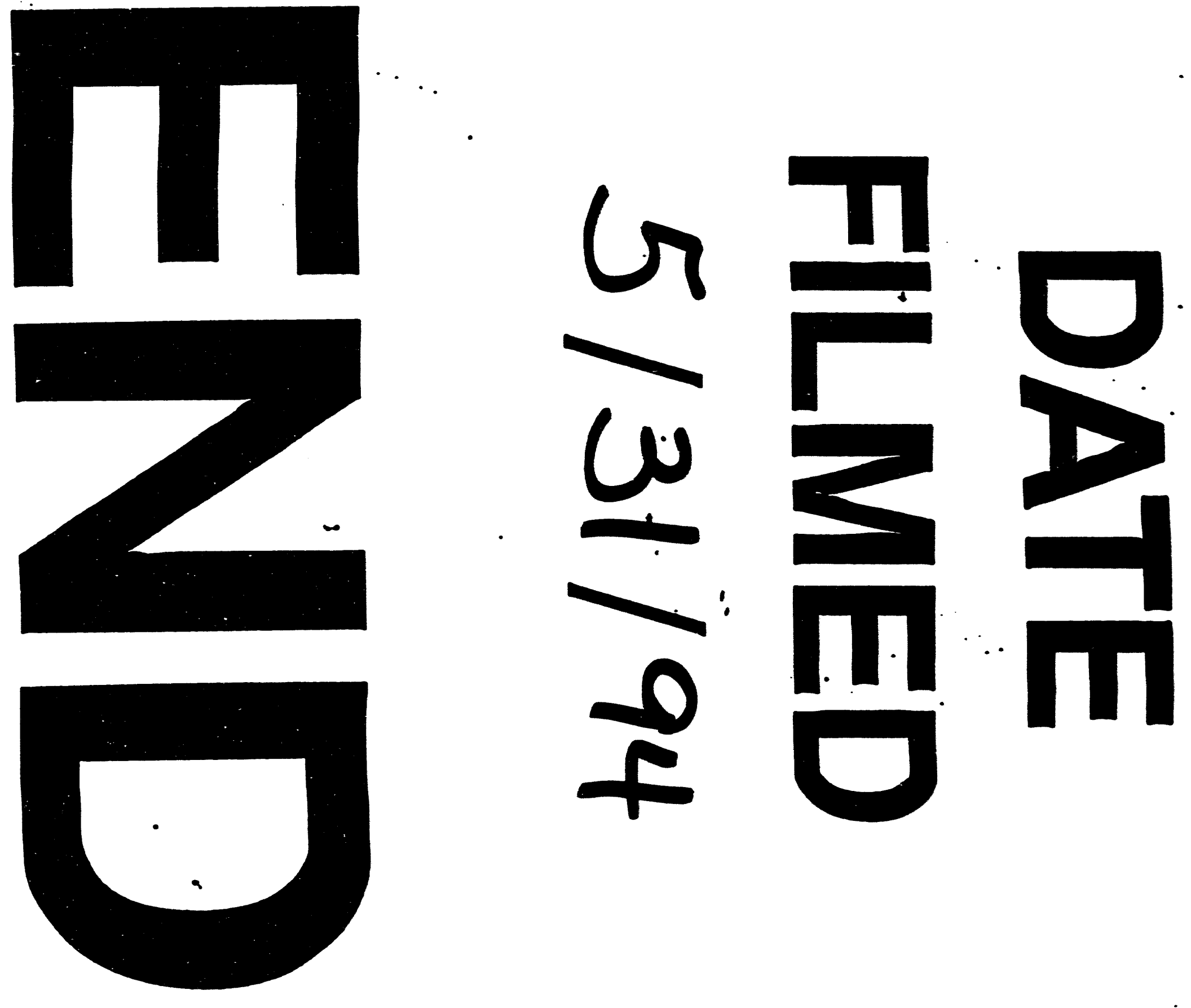


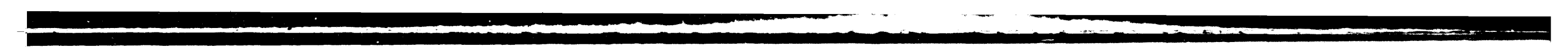

